\title{
The seismic coupling of subduction zones revisited
}

\author{
Christopher H. Scholz ${ }^{1}$ and Jaime Campos ${ }^{2}$ \\ Received 8 November 2011; revised 24 March 2012; accepted 26 March 2012; published 18 May 2012.
}

[1] The nature of seismic coupling for many of the world's subduction zones has been reevaluated. Geodetic estimates of seismic coupling obtained from GPS measurements of upper plate deformation during the interseismic period are summarized. We compared those with new estimates of seismic coupling obtained from seismological data. The results show that with a few notable exceptions the two methods agree to within about $10 \%$. The seismological estimates have been greatly improved over those made 20-30 years ago because of an abundance of paleoseismological data that greatly extend the temporal record of great subduction earthquakes and by the occurrence, in the intervening years, of an unusual number of great and giant earthquakes that have filled in some of the most critical holes in the seismic record. The data also, again with a few notable exceptions, support the frictional instability theory of seismic coupling, and in particular, the test of that theory made by Scholz and Campos (1995). Overall, the results support their prediction that high coupling occurs for subduction zones subjected to high normal forces with a switch to low coupling occurring fairly abruptly as the normal force decreases below a critical value. There is also considerable variation of coupling within individual subduction zones. Earthquake asperities correlate with areas of high coupling and hence have a semblance of permanence, but the rupture zones and asperity distributions of great earthquakes may differ greatly between seismic cycles because of differences in the phase of seismic flux accumulation.

Citation: Scholz, C. H., and J. Campos (2012), The seismic coupling of subduction zones revisited, J. Geophys. Res., 117, B05310, doi:10.1029/2011JB009003.

\section{Introduction}

[2] It has long been known that subduction zones vary greatly in their degree of seismic coupling. There have been many efforts to compile these differences [Jarrard, 1986; Pacheco et al., 1993; Peterson and Seno, 1984; Uyeda, 1982] as well as attempts to explain them [e.g., Ruff and Kanamori, 1980, 1983; Scholz and Campos, 1995]. Seismic coupling is defined as the ratio, $\chi_{S}=\frac{\dot{M}_{o}^{s}}{\dot{M}_{o}^{T}}$ between the observed seismic moment release rate $\dot{M}_{o}^{s}$ and the rate calculated from plate tectonic velocities $\dot{M}_{o}^{T}$. In the studies of the era cited above, $\dot{M}_{o}^{s}$ was estimated by summing the moments of earthquakes that had occurred during the instrumental era in a given subduction zone and dividing that by the observation period, a procedure with well known

\footnotetext{
${ }^{1}$ Lamont-Doherty Earth Observatory, Earth Institute at Columbia University, Palisades, New York, USA.

${ }^{2}$ Departmento de Geophisica, Universitad de Chile, Santiago, Chile.

Corresponding author: C. H. Scholz, Lamont-Doherty Earth Observatory, Earth Institute at Columbia University, Palisades, NY 10964, USA. (scholz@1deo.columbia.edu)

Copyright 2012 by the American Geophysical Union. 0148-0227/12/2011JB009003
}

uncertainties and biases [cf. McCaffrey, 1997]. With the advent of monitoring of subduction zones with GPS receivers, it has been possible to directly invert for the seismic coupling coefficient $\chi_{G}$ from the interseismic strain accumulation rate of the upper plate, and this has now been done in many subduction settings. This geodetic estimate of seismic coupling is free of most of the uncertainties of the earlier method, which mainly involve problems of sampling rare events. Furthermore, whereas the earthquake summing measurement was a measure of energy release rate, the geodetic measurement is a measure of energy accumulation rate. Under the assumption that seismic coupling is constant over the interseismic period, these two must balance in the long-term. The extent to which they disagree reveals our ignorance of the seismic activity of a region and also allows us to quantitatively estimate the size of the missing elements and to look for them in the paleoseismic or older historic record.

[3] The time scale over which we have knowledge of subduction zone earthquakes has expanded greatly in recent years due to various paleoseismological techniques such as the study of coastal uplift from corals and of tsunami deposits, allowing for better estimates of $\chi_{S}$. Furthermore, over the past twenty years there have been an unusual number of great $M_{w} 8-9$ earthquakes which have filled in a number of critical holes in the seismic record. For all of 
these reasons, it is fitting to revisit the topic of seismic coupling at subduction zones.

\section{Theory and Methods}

\subsection{Seismic Flux Rates and the Energy Balance}

[4] A quantitative measure of the rate of seismic contribution to tectonic deformation in a region is given by

$$
\dot{P}_{S}=\sum_{i=1}^{n} \frac{M_{o}^{i}}{\mu T^{i}}
$$

where $M_{o}^{i}$ is the moment of the $i$ th earthquake, $T^{i}$ is its recurrence time, and $\mu$ is the shear modulus. The parameter that is central to this topic is defined as

$$
P_{S}=\frac{M_{o}}{\mu}=\int_{S} u d A
$$

where $u$ is the slip vector and $d A$ is the rupture area. Such a surface integral of a vector field is mathematically defined as a flux and this term is often used in physics for the same type of quantity, i.e., the electric flux. We therefore call $P_{S}$ the seismic flux $\left(P_{S}\right.$ has also been called 'potency', but since that term provides little physical insight, we avoid it.). The time derivative $\dot{P}_{s}$, with units $\mathrm{m}^{3} / \mathrm{yr}$, is hence the seismic flux release rate. For convenience, we define a seismic flux rate unit, $\Phi=10^{9} \mathrm{~m}^{3} / \mathrm{yr}$. The seismic coupling coefficient is then defined as $\chi_{S}$, where

$$
\chi_{S}=\frac{\dot{P}_{S}}{\dot{P}_{T}}
$$

in which the tectonic flux rate $\dot{P}_{T}=v_{p} A_{c}$, the product of the plate motion velocity and the area of plate coupling.

[5] If we have geodetic measurements of the interseismic velocity field of the upper plate, a third parameter, $\dot{P}_{G}$, the seismic flux accumulation rate, can be determined. With the assumption that this parameter is constant during the interseismic period (this requires that measurements be taken after the postseismic effects of the last great earthquake have decayed into the background), the geodetic coupling coefficient

$$
\chi_{G}=\frac{\dot{P}_{G}}{\dot{P}_{T}}
$$

provides a much more robust measure of the frictional characteristics of the plate interface than does (3).

[6] Evidence from uplifted terraces along the Nankai coast [Fitch and Scholz, 1971] and corals off Sumatra [Briggs et al., 2008; Sieh et al., 2008] indicate that permanent uplift constitutes less than $5 \%$ of the coseismic uplift in the subduction zone seismic cycle. We can, therefore, assume that essentially all the deformation measured in $\dot{P}_{G}$ is elastic and that on the long-term, over several seismic cycles, the equilibrium condition must hold:

$$
\dot{P}_{G}=\dot{P}_{S}
$$

Because $P_{S}$ is related to seismic energy by $P_{S}=\frac{2}{\Delta \sigma} E_{S}$, [Scholz, 2002, equation 4.27, p. 201] (5) is an energy balance statement. This equation provides an independent check on estimates of $\dot{P}_{S}$ which allow for the assessment of the completeness of the historic and prehistoric earthquake records and, in cases where there is a significant shortfall in the seismic flux release rate, a quantitative estimate of the seismic activity that must be missing from the record.

\subsubsection{Measurement Methods and Uncertainties}

[7] There are two types of uncertainties associated with estimating $\dot{P}_{S}$ with equation (1). The primary one is the problem of sampling sparse data. Because the seismic flux release rate is dominated by the few largest events, the number of events $n$ in each evaluation is small and the sample duration, $t_{o}$, is usually $\leq T$, the recurrence time of the largest events. This can lead to either under- or overestimates of $\dot{P}_{S}$. This is because we do not usually know $T$ for each event, so the practice has often been to use $t_{o}$ as a proxy for $T$ [e.g., Pacheco et al., 1993]. This will usually lead to over-estimates of $\dot{P}_{S}$. Great earthquakes in subduction zones, with a very few exceptions, have aspect ratios L/W less than 10 , so that average slip $\bar{u} \propto L$ [Scholz, 2002, pp. 206-207]. Therefore, $T$ will increase with magnitude, which means that the probability of missing the largest events in a given interval $t_{o}$ increases with the size of the event, which leads to underestimating $\dot{P}_{S}$. (It is usually found that this error dominates.) Here we try to reduce this error by using estimates of $T$ for the individual largest events (including some missing from the historic record) by incorporating paleoseismological data for them. None of these kinds of errors are associated with $\dot{P}_{G}$, for which the uncertainties are of the more tractable type associated with inverse problems.

[8] There are also uncertainties in estimating the coupling area $A_{c}$. What is meant by this parameter is the area of the plate interface that undergoes co-seismic slip and which is often called the seismogenic area. The length of this area is usually the length of the plate boundary segment chosen for study (although, as we shall see, it excludes end-regions near segment boundaries). Greater uncertainty arises from estimating the coupled width, $W_{c}$. In a simple model of the subduction zone interfaces, shown in Figure 1a, $W_{c}$ extends from somewhere within or near the base of the accretionary prism to the depth of the brittle plastic transition, which typically occurs at a temperature of $\sim 350^{\circ} \mathrm{C}$ [Tichelaar and Ruff, 1993; Wang et al., 2003]. Below this is a transitional region of intermediate coupling where the slip is accommodated by slow slip events (SSEs), below which the plate interface slips freely at the plate tectonic rate. The width $W_{c}$ can be determined by three methods: from the locations of background seismicity, the rupture areas of great earthquakes, or from the inversion of GPS data for the area of interseismic coupling. The uncertainties in the first two methods lead to an overall uncertainty in $A_{c}$ of about $30 \%$ [Pacheco et al., 1993] whereas the addition of the third method, which is the one mainly used in this paper, considerably reduces that uncertainty. The inversion of GPS data usually does a good job of determining the downdip limit of $A_{c}$ but a poorer job of estimating the updip limit, which is usually far offshore and hence poorly resolved by land-based instruments. 

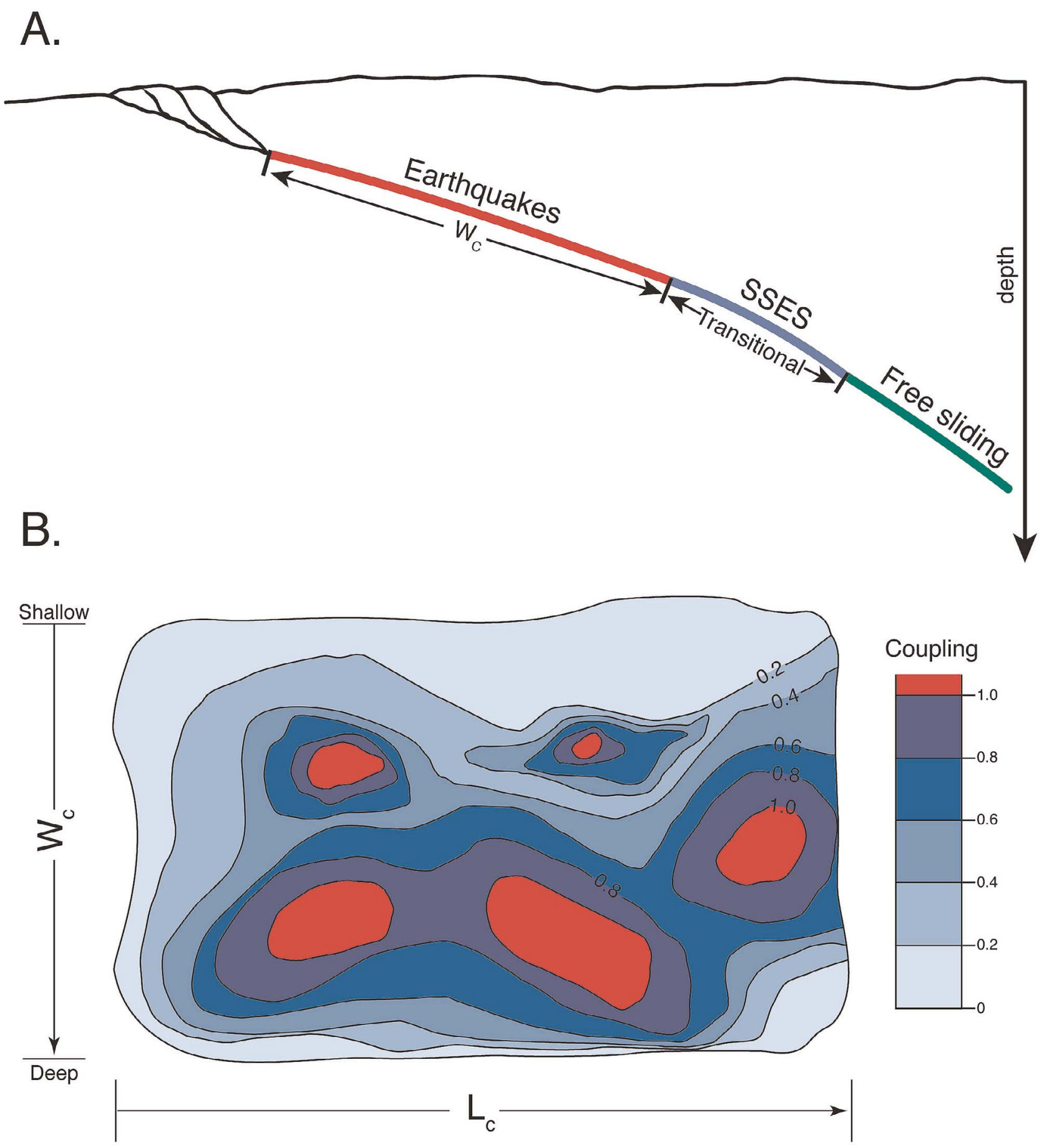

Figure 1. (a) Schematic cross-section of a subduction zone showing the coupled (seismogenic) width $W_{C}$. Below that is a transitional region of partial coupling in which the slip occurs in slow slip events (SSEs). (b) A cartoon of seismic coupling on the coupled area $A_{C}$.

[9] Another source of uncertainty is the appropriate value of the shear modulus to use when converting seismic moment to seismic flux. We use a value of $4 \times 10^{10} \mathrm{Nm}^{-2}$, which is an average of the lower crust and upper mantle in the PREM standard earth model.

\subsection{Frictional Instability Theory of Seismic Coupling}

[10] The basic elements of this theory were described in Scholz and Campos [1995], but here we discuss it in more detail using some further concepts from the rate/state friction constitutive law as it applies to subduction zones [Scholz, 1998]. From the standpoint of R/S friction, the coupled width $W_{c}$ as defined above corresponds to the velocityweakening regime, i.e., where the friction rate parameter $(a-b)<0$. Within that regime there are two stability states, unstable, where the sliding is unstable under quasi-static loading, and conditionally stable, where the sliding is stable under quasi-static loading but may become unstable 
under dynamic loading above a threshold velocity kick. A region in the unstable regime undergoes pure stick-slip; all slip is unstable and its seismic coupling coefficient $\chi=1$. Earthquakes can nucleate only within the unstable field but they may propagate into the conditionally stable field. For a region in the conditionally stable state, $0<\chi<1$. The stability boundary between these states occurs at a critical effective normal stress:

$$
\bar{\sigma}_{c}=\frac{\kappa D_{c}}{(b-a)}
$$

where $\kappa$ is a stiffness and $D_{c}$ is another frictional parameter called the critical slip distance. Any region within $A_{c}$ where the normal stress exceeds this critical value will be in the unstable state - all other regions will be conditionally stable.

[11] The contacting subduction zone interface surfaces are not planar, but irregular, presumably fractal. Therefore the local normal stress acting between them will vary spatially. A sketch of the expected coupling on such a surface, shown in Figure 1b, reflects this heterogeneity in $\bar{\sigma}$. The unstable regions, shown in red, are stuck patches, and the conditionally stable (blue) areas surrounding them are dragged along passively. What results is a topography of flat-topped hills, or "mesas," in the map of seismic flux accumulation rate, or, when normalized to the tectonic rate, the seismic coupling coefficient.

[12] The sketch of Figure $1 \mathrm{~b}$ was drawn with a region of intermediate coupling in mind. The effect of increasing the normal force across the entire contact area would be to grow and merge the red areas and have new ones appear, resulting in an overall higher coupling coefficient for the subduction zone. Decreasing the normal force would make the red zones shrink and eventually disappear, with the end result being a decoupled subduction zone. This effect of normal force is what Scholz and Campos [1995] were testing by comparing seismic coupling to the relative normal forces on subduction zone interfaces as calculated from plate tectonic forces.

\subsubsection{Interpretation in Terms of the Asperity Concept}

[13] One or more areas of enhanced slip generally typify the slip distribution in great subduction zone earthquakes. Such areas of enhanced slip have been called asperities [Lay et al., 1982] and this terminology has enjoyed widespread usage. Although the term asperity intuitively implies a connotation of 'strength', the asperity concept has never been placed on a firm physical basis. It arises, however, quite naturally from the frictional instability seismic coupling theory, where its meaning becomes clear.

[14] If we integrate the seismic flux accumulation rate with time, we will obtain a figure similar to Figure $1 \mathrm{~b}$ showing the accumulated seismic flux (sometimes called 'slip deficit'). Earthquake nucleation can occur only within the unstable areas, so rupture will initiate at the top of one of the mesas and the extent of the rupture will be determined by the local topography of accumulated seismic flux (which maps into a distribution of local shear stress excess). The local coseismic slip in the earthquake should be closely related to the local accumulated seismic flux and therefore share the same hilly topography of the latter, with each slipprominence within the rupture being called an asperity. This results in the first generalization that has been made about such earthquakes: that the hypocenter lies near or within one of the asperities [Thatcher, 1990].

[15] Figure $1 \mathrm{~b}$ was drawn to indicate that coupling increases with depth - reflecting the increase of $\bar{\sigma}$ with depth. This explains the other generalization made by Thatcher [1990] about great subduction zone earthquakes: their asperities tend to lie near their deeper edges.

[16] The greater issue regarding asperities has always been whether they are permanent or ephemeral features. The distribution of the seismic coupling coefficient on a subduction interface is a permanent feature (at least on a time scale much longer than the seismic cycle). This determines the seismic flux accumulation rate, a velocity field. The rupture extent and slip distribution of an earthquake depends on the field of accumulated seismic flux, which depends on both the velocity and phase of the flux accumulation. Although the velocity field is a permanent feature, its local phase depends on when the slip was last reset in an earthquake and is heterogeneous in space and time: it depends on the history of past earthquakes, which is a fading unknown.

[17] The unstable regions in red in Figure $1 \mathrm{~b}$ will always have the highest coupling coefficient and hence tend to form local maxima in seismic flux. But because their local slip history in past earthquakes is varied, their accumulated seismic fluxes will have different relative amplitudes in different seismic cycles. Because of this, great earthquakes in a given subduction zone will not be exact replicas of one another, with the same collection of asperities, but will consist of various combinations that share a familial resemblance. There will be a correlation of asperities with patches of high coupling, but it will not be an exact one. Many examples of these features will be described in the observational sections that follows.

[18] In the following sections we will refer to the model presented in Scholz and Campos [1995] as the SC95 model. This model attempts to predict the average seismic coupling on a subduction zone scale. There are also along-strike variations in seismic coupling within individual subduction zones. Whereas these variations may also arise from alongstrike variations in $\bar{\sigma}$, they may also arise from other causes. It has been suggested, for example, that such variations may arise from seamount subduction [Scholz and Small, 1997] or correlate with basins [Wells et al., 2003]. These issues will be addressed in the discussion section.

\section{Summary of New Observations}

[19] In this section we summarize recent results for seismic coupling on a case-by-case basis. These are presented in Table 1. The cases presented here are those in which determinations of $\dot{P}_{G}$ have been made and/or for which new great earthquakes have occurred or new paleoseismological information has become available that significantly modify our understanding of $\dot{P}_{S}$.

\subsection{Honshu}

[20] This is the portion of the Japan trench that extends from its triple junction with the Sagami and Izu-Bonin trenches in the south to the cusp with the Kuril trench between Honshu and Hokkaido (Figure 2). The seismic coupling of this region was estimated from the inversion of pre-2011 GPS data by Hashimoto et al. [2009], Loveless and Meade 
Table 1. Subduction Zone Coupling Parameters

\begin{tabular}{|c|c|c|c|c|c|c|c|c|c|}
\hline Subduction Zone & $\Delta \mathrm{F}_{\mathrm{n}}\left(\mathrm{N}-\mathrm{m}^{1} \times 10^{12}\right)$ & $\dot{P}_{s}\left(10^{9} \mathrm{~m}^{3} / \mathrm{yr}\right)$ & $\dot{P}_{g}\left(10^{9} \mathrm{~m}^{3} / \mathrm{yr}\right)$ & $\frac{\dot{P}_{S}-\dot{P}_{G}}{\dot{P}_{G}}$ & $\chi_{\mathrm{s}}$ & $\chi_{\mathrm{g}}$ & $W_{c}(\mathrm{~km})$ & $L_{c}(\mathrm{~km})$ & $v_{\mathrm{p}}(\mathrm{mm} / \mathrm{yr})$ \\
\hline Honshu & 1.5 & $3.0-3.3$ & $3.1-3.7$ & 0.06 & 0.59 & $0.54-.65$ & 110 & $625^{\mathrm{a}}$ & 83 \\
\hline Hikurangi & 4.1 & 0 & 0 & 0 & 0 & 0 & - & $-{ }^{b}$ & \\
\hline Kamchatka & 1.79 & 6.75 & $6.4-8.9^{c}$ & -0.11 & 0.51 & $0.48-.67$ & 160 & 1000 & 83 \\
\hline Kuriles & 2.52 & 5.3 & & & 0.59 & & 180 & 1350 & 83 \\
\hline Nankai/Tokai & 0.17 & & & 0 & 1.0 & 1.0 & & & 55 \\
\hline Cascadia & 0.04 & $2.7^{\mathrm{d}}$ & 2.6 & 0.04 & 1.0 & 1.0 & 60 & 1100 & 40 \\
\hline Ryukyus & n.a. & & 0 & 0 & 0.0 & 0.0 & & & \\
\hline Hokkaido & 2.52 & $3.1^{\mathrm{e}}$ & 2.9 & 0.07 & 0.66 & 0.62 & 115 & 500 & 83 \\
\hline Central Chile & 0.44 & 2.9 & 4.1 & -0.29 & 0.70 & 1.0 & 130 & 450 & 68 \\
\hline South Chile & 0.10 & $6.2-9.3$ & 7.3 & 0.06 & $0.82-1.0$ & 0.96 & 130 & 850 & 69 \\
\hline North Chile & -0.47 & 3.4 & 3.6 & -0.02 & 0.94 & 1.0 & 102 & 450 & 79 \\
\hline Sumatra & 0.63 & $5.4-9.0$ & 10.8 & -0.33 & $0.5-0.83$ & 1.0 & 150 & 1600 & 45 \\
\hline N. Tonga & 1.26 & 2.1 & & n.a. & 0.65 & & 68 & 550 & 80 \\
\hline Central Aleutians & 0.42 & 1.4 & 1.64 & -0.15 & 0.82 & 0.96 & 80 & 350 & 61 \\
\hline Alaska & 0.35 & $3.5-5.0$ & 4.3 & -0.01 & $0.5-0.72$ & 0.62 & 160 & 500 & 55 \\
\hline E.Aleutians, Samedi Is. & 0.4 & $1.1-2.5$ & 1.9 & -0.05 & $0.55-0.8$ & 0.80 & 180 & 400 & 59 \\
\hline E. Aleutians Shumagin Is. & 0.4 & n.r. & 0.2 & & & 0.30 & 84 & 125 & 63 \\
\hline Central Peru & -1.29 & 3.2 & 2.9 & -0.07 & 0.80 & 0.75 & 130 & 500 & 61 \\
\hline South Peru & -1.29 & 2.9 & & & 0.75 & & 107 & 500 & 62 \\
\hline Colombia-Ecuador & 0.12 & & 1.3 & & & 0.50 & 90 & 500 & 58 \\
\hline Central America & 0.26 & 0.74 & 1.7 & -0.61 & 0.10 & 0.20 & 106 & 850 & 85 \\
\hline Mexico & 0.15 & 1.5 & 1.4 & -0.07 & 1.0 & 0.9 & 50 & 550 & 57 \\
\hline
\end{tabular}

${ }^{\text {a }}$ South end decoupled.

${ }^{\mathrm{b}}$ South end coupled.

${ }^{\mathrm{c}}$ Coupling decreases to north.

${ }^{\mathrm{d}} \mathrm{M}_{\mathrm{w}} 9.1 \mathrm{~T}=520$.

${ }^{\mathrm{e}} \mathrm{M}_{\mathrm{w}} 8.8 \mathrm{~T}=400$.

[2010], and Suwa et al. [2006]. The results of those three studies were similar at wavelengths greater than $100-150 \mathrm{~km}$ [Loveless and Meade, 2011]. $\dot{P}_{G}$ values determined for each model were $3.2,3.7$, and $3.1 \Phi$, respectively. This may provide an idea of the uncertainty of this parameter. The plate velocity is $83 \mathrm{~mm} / \mathrm{yr}$, from which we calculate the tectonic flux rate as $5.7 \Phi$, and therefore $\chi_{\mathrm{G}}=0.54-.65$. The seismic flux sum for the 90-year period considered by Pacheco et al. [1993] was $1.5 \times 10^{11} \mathrm{~m}^{3}$, yielding a seismic flux release rate of $1.7 \Phi$, and $\chi_{\mathrm{s}}=0.30$. Hence the instrumental record underestimates the long-term seismic potential of this region by almost a factor of two.

[21] The blue area in Figure 2 indicates seismic coupling, contoured in intervals of $3 \mathrm{~cm} / \mathrm{yr}$, from Hashimoto et al. [2009]. Red contours give the slip distribution of the 2011 $\mathrm{M}_{\mathrm{w}} 9.1$ Tohoku-oki earthquake [Simons et al., 2011]. That earthquake initiated in a region of high coupling, but was unusual in having high slip at shallow depths. Because the resolution of coupling decreases rapidly with distance from the coast, it is not possible to distinguish whether the shallow slip occurred in an area of low coupling [Loveless and Meade, 2011] or, whether, by dynamic overshooting, it ruptured into an area of velocity strengthening [Ide et al., 2011].

[22] The most likely precedent of the Tohoku-oki earthquake was the Jogan earthquake of 869 . Reports of tsunamis for that earthquake came from 36 to $39^{\circ}$ along the Pacific coast of Tohoku, and its tsunami deposits on the Sendai plain extended more than $4 \mathrm{~km}$ inland [Minoura et al., 2001]. The same study found two earlier events of similar size during the previous 3000 years. Such events thus have recurrence times of $\sim 1000$ years. Estimates of the moment of the 2011 earthquake range from the seismically determined $5.3 \times 10^{22} \mathrm{~N}-\mathrm{m}[$ Nettles et al., 2011] to the geodetically determined $6.5 \times 10^{22} \mathrm{~N}-\mathrm{m}$ ([Simons et al., 2011], using their estimate of areas that slipped in excess of $10 \%$ of the maximum slip). Dividing the equivalent seismic fluxes by the recurrence time of 1000 years yields a $\dot{P}_{S}$ from that earthquake of 1.3-1.6 $\Phi$. Thus the 2011 Tohoku-oki earthquake almost doubled the estimated long-term seismic flux release rate Ps for this region to $3.0-3.3 \Phi$, bringing it into approximate agreement with the estimates of $\dot{P}_{G}$. The seismic hazard for this regions therefore seems to be mainly accounted for, with about half of Ps coming from giant earthquakes that rupture almost the entirety of Ac with recurrence times of order 1000 years and the other half from more frequent ( $T \sim 100 \mathrm{yr}$ or less) large earthquakes that rupture smaller portions of Ac. In the region off Sendai, seismic coupling is characterized by a ridge, with several maxima defining local asperities (Figure 2). The pre-2011 seismic history consisted of $\mathrm{Mw}$ 7.5-7.8 Miyagi-oki and Fukushima-oki earthquakes rupturing those local asperities at frequent $(\sim 30-50 \mathrm{yr})$ intervals. The 2011 earthquake, by contrast, ruptured all the asperities and the entire coupled ridge. We imagine this happening at the infrequent times when all of these asperities come into phase with one another. What are observed are small local epicycles operating within the larger system-sized cycles.

[23] The coupled area $A_{c}$ defined by Hashimoto et al. [2009] (Figure 2) has a southern terminus at $\sim 36^{\circ} \mathrm{N}$, some $200 \mathrm{~km}$ north of the triple junction with the Philippine Sea Plate. This end region is anomalous in many ways and appears to be seismically decoupled [Seno and Takano, 1989; Uchida et al., 2009]. This is possibly because the nearby TTT triple junction is unstable and therefore migrating, or because of interactions between the subducting Philippine Sea and Pacific plate slabs, either of which could induce local forces on the plates not considered in the $2 \mathrm{D}$ analysis of SC95. 


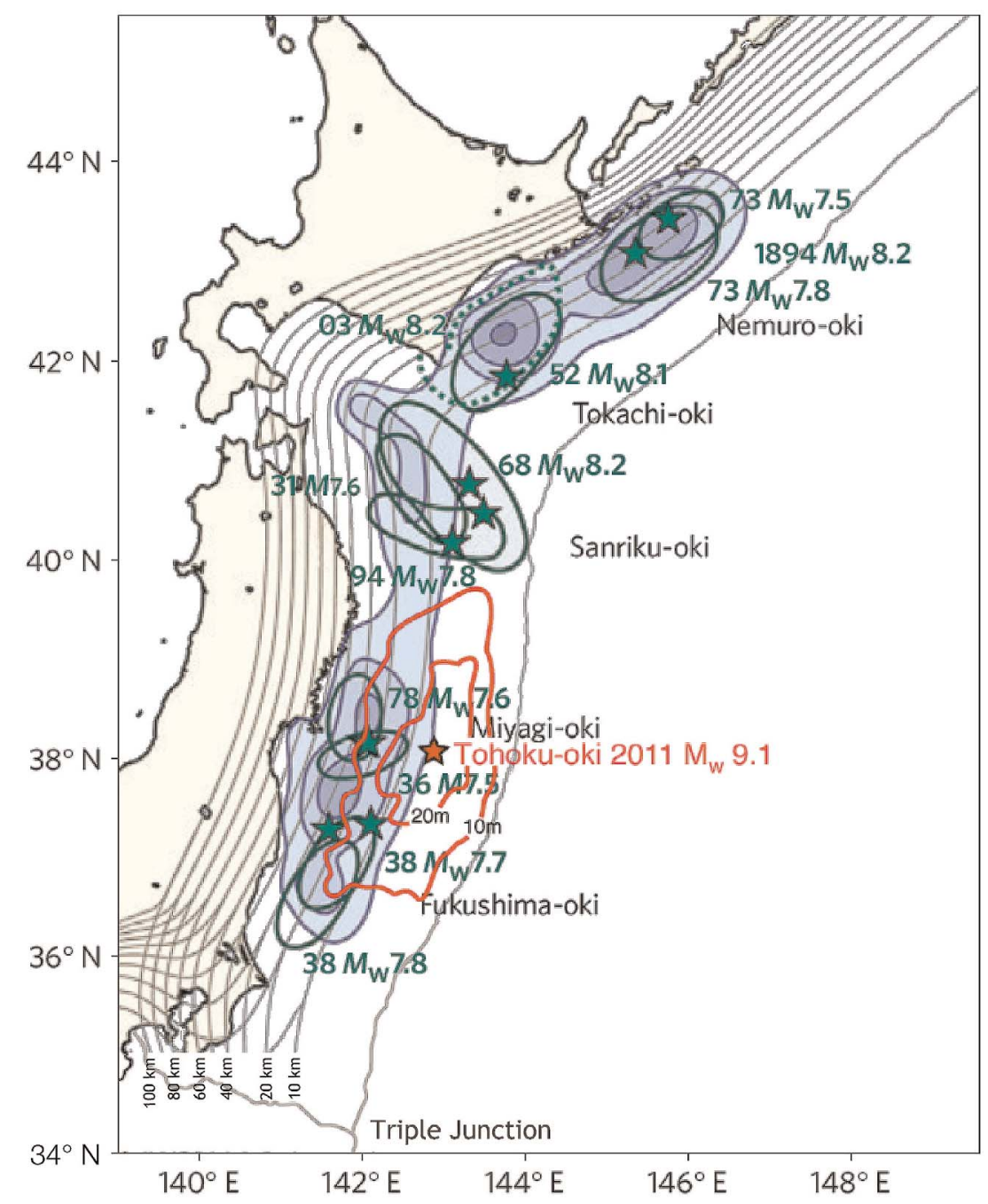

Figure 2. Seismic coupling of Japan, in $3 \mathrm{~cm} / \mathrm{yr}$ contours, from Hashimoto et al. [2009]. Red contours are 2011 Tohoku-oki earthquake [Simons et al., 2011].

\subsection{Kamchatka}

[24] The Kamchatka segment extends from the southern end of the 1952 rupture north to the cusp with the Aleutian arc, a distance of $1000 \mathrm{~km}$.

[25] The seismic moment release rate for this region is dominated by the 1952 Kamchatka earthquake $\left(\mathrm{M}_{\mathrm{w}} 9.0, \boldsymbol{P}_{\boldsymbol{s}}=\right.$ $\left.8.5 \times 10^{11} \mathrm{~m}^{3}\right)$. The other 20th century earthquakes were $1904\left(\mathrm{M}_{\mathrm{w}} 8.0\right), 1923\left(\mathrm{M}_{\mathrm{w}} 8.5\right), 1959\left(\mathrm{M}_{\mathrm{w}} 8.2\right)$, and 1997 $\left(\mathrm{M}_{\mathrm{w}}\right.$ 7.8), which together sum to a seismic flux of $2.5 \times$ $10^{11} \mathrm{~m}^{3}$. The most probable predecessor of the 1952 event was the great earthquake of 1737 , hence such earthquakes probably have a recurrence time of $\sim 200$ yrs [Johnson and Satake, 1999; McCann et al., 1979] Using this for the recurrence time of the 1952 earthquake and 100 years for the others yields a net value of $\boldsymbol{P}_{s}=6.75 \Phi$.

[26] Burgmann et al. [2005] found that the interseismic upper plate deformation was best fit with a model in which full coupling was assumed in the asperity zones of the historic earthquakes. They used a series of 5 models in which $\boldsymbol{P}_{G}$ was found to lie in the range 6.4-8.9 $\Phi$. A simple model of the coupled region dips $15^{\circ}$ from 10 to $50 \mathrm{~km}$ depth, for a width of $160 \mathrm{~km}$, length $1000 \mathrm{~km}$, and a coupled area $A_{c}=$ $16 \times 10^{10} \mathrm{~m}^{2}$. If this were fully coupled at $80 \mathrm{~mm} / \mathrm{yr}$, we obtain $\dot{P}_{T}=12.8 \Phi$, from which we obtain coupling coefficients $\chi_{\mathrm{s}}=0.52$ and $\chi_{\mathrm{g}}=0.50-0.70$. Within the uncertainty, this region appears to be in balance.

[27] Pacheco et al. [1993] and Burgmann et al. [2005] both noted that the coupling is significantly reduced beyond the northern end of the 1952 rupture $\left(53^{\circ} \mathrm{N}\right)$. The two-plane models of Burgmann et al. indicate that this may occur by the coupled width narrowing to the north. Whether or not this is an end effect associated with the Aleutian cusp is unknown.

\subsection{Kuriles}

[28] This zone extends from the southeastern cape of Hokkaido to the southern end of the 1952 Kamchatka rupture zone. The central part of the Kuriles was known as a well defined seismic gap some $500 \mathrm{~km}$ long that had not experienced a significant rupture within the limited historic period [Nishenko, 1991]. The nature of its coupling had been a matter of some speculation: [Song and Simons, 2003], in 
proposing a model in which seismic decoupling should be favored in areas of positive trench parallel gravity anomalies, presented the Kuriles gap as a likely decoupled area. SC95, in contrast, predicted that the Kuriles are well coupled. Such debate was put to rest by the occurrence in 2006 of a $\mathrm{M}_{\mathrm{w}} 8.3$ earthquake that ruptured the southern two-thirds of this gap [Lay et al., 2009].

[29] Pacheco et al. [1993] divided this region into two portions, a northern one largely comprised of the gap and hence with a very low coupling ration of 0.07 , and a southern part with a coupling coefficient of 0.73 . We combined the two areas, and, adding the $M_{w} 8.32006$ Kurile and $\mathrm{M}_{\mathrm{w}} 8.22003$ Tokachi-oki earthquakes and using a longer averaging time of $110 \mathrm{yrs}$, obtained an combined value of $\chi_{\mathrm{s}}=0.59$.

\subsection{Hokkaido}

[30] If we consider only the portion of the Kurile trench off Hokkaido, geodetic estimates of $\dot{P}_{G}=2.9 \Phi$ and $\chi_{G}=$ 0.62 were calculated from the results of Hashimoto et al. [2009] shown in Figure 2. The sum of earthquakes in that sector for the past 100 years: the Tokachi-oki earthquakes of 1952 and $2003\left(\mathrm{M}_{\mathrm{w}} 8.1\right.$ and 8.2), which ruptured the southern half of that sector, and the Nemuro-oki earthquakes of 1894 and $1973\left(\mathrm{M}_{\mathrm{w}} 8.2\right.$ and 7.8$)$, which ruptured the northern portion, accounts for only about half this value $\left(\boldsymbol{P}_{\boldsymbol{s}}=1.85 \Phi, \chi_{\mathrm{s}}=0.39\right)$. This discrepancy indicates that the historic record seriously underestimates the seismic activity: that something must be missing from the record. This missing element was found in the form of tsunami deposits along the east coast of Hokkaido which indicate that much larger earthquakes, with rupture lengths of $\sim 500 \mathrm{~km}$, more than twice that of the historic events, occur there with average recurrence times of about 400 years, with the most recent having occurred about 350 years ago [Nanayama et al., 2007, 2003; Sawai et al., 2009]. According to an empirical relation between $\mathrm{M}_{\mathrm{w}}$ and $L$ for subduction zone events [Dorbath et al., 1990], a $500 \mathrm{~km}$ long earthquake corresponds to an $\mathrm{M}_{\mathrm{w}}$ 8.8. Such an event occurring every 400 years would increase $\boldsymbol{P}_{\mathrm{s}}$ to $3.1 \Phi$, within the margin of uncertainty of our estimate of $\dot{P}_{G}$. This calculation is the same as one that could have been done prior to the 2011 Tohoku-oki earthquake because the same types of data were then available for that region. The partitioning of seismic hazard between rare fullsegment rupturing events and more frequent partial-segment rupturing events is very similar in these regions.

\subsection{Nankai/Tokai}

[31] This region comprises the Nankai trough subduction zone between the Philippine Sea Plate and the Eurasian Plate in southwest Japan. It has one of the best-documented earthquake histories and is the archetype of a coupled subduction zone. Inversion of interseismic GPS data show that the region off Shikoku and the Kii peninsula is fully locked from 8 to $25 \mathrm{~km}$ depth [Mazzotti et al., 2000]. More precise analysis indicates that the coupled depth goes to $30 \mathrm{~km}$ with a transition zone to $40 \mathrm{~km}$. [Aoki and Scholz, 2003]. The transition zone has a coupling coefficient of $0.3-0.5$, which is accommodated by slow slip events [Obara, 2010]. The Tokai region, just to the northeast, is also fully coupled [Sagiya, 1999] but in the northeastern part of Suruga Bay coupling decreases and becomes more complicated. This latter may be an end effect: it is just adjacent to the cusp with the Sagami trough and the collision of the Izu Peninsula.

[32] Earthquake data for the last three seismic cycles also indicate that this region is fully coupled within the context of the time-predictable model and the inclusion of postseismic relaxation [Ando, 1975; Sagiya and Thatcher, 1999; Scholz, 2002, pp. 265-269; Sykes and Menke, 2006].

[33] The long earthquake history of this area shows that it may be divided into four or five segments that rupture either individually or in various contiguous combinations [Ando, 1975; Sykes and Menke, 2006]. This is another example of the variability within familial constraints that typify great subduction earthquakes.

\subsection{Ryukyus}

[34] The Ryukyus is an extensional arc, accompanied by back-arc spreading in the Okinawa trough, and is thought to be seismically decoupled [e.g., McCann et al., 1979]. The inversion of GPS data show that Kyushu is not accumulating any strain from subduction on the northern Ryukyu trench off its eastern shore [Ito et al., 1999]. There are no known great subduction earthquakes in that area, which is characterized by repeating $\mathrm{M}_{\mathrm{w}} 7$ earthquakes in Hyuganada. The southwestern part of the arc in which the strike becomes closer to parallel with the plate motion direction is also thought to be weakly coupled [Kao, 1998], with earthquakes not typically exceeding $\mathrm{M}_{\mathrm{w}} 7.4$, although an event of 1771 has been recognized as an $\mathrm{M}_{\mathrm{w}} 8.0$ tsunami earthquake [Nakamura, 2009]. This will not affect the conclusion that this zone is very weakly coupled. A nearby region in the southern Ryukyus is observed to move in periodic slow slip events over almost the entire subduction contact area [Heki and Kataoka, 2008]. They provide the entire plate tectonic slip rate, indicating that this region is in the episodic slip mode of the conditionally stable regime.

[35] The SC95 model does not provided a meaningful value of $\Delta \mathrm{F}_{\mathrm{N}}$ for this case. Two eastward-directed subduction zones bound the Philippine Sea plate. This requires the Ryukyu and Izu-Bonin slabs to migrate toward one another. This imposes roll-back on the Ryukyus and requires that arc to be extensional. The SC95 model analyzes each subduction zone as an isolated mechanical system, hence cannot deal with coupled systems like the Ryukyus.

\subsection{Sumatra}

[36] This subduction zone, having experienced no great subduction earthquakes in the 20th Century, was the site of the great $\mathrm{M}_{\mathrm{w}}$ 9.2 Sumatra-Andaman earthquake of 2004 [Ammon et al., 2005; Lay et al., 2005; Subarya et al., 2006], the adjoining $\mathrm{M}_{\mathrm{w}} 8.7$ Nias-Simeulue earthquake of 2005 [Briggs et al., 2006] and an $\mathrm{M}_{\mathrm{W}} 8.4$ event further to the south in 2007 [Konca et al., 2008]. Previous great earthquakes had occurred in the 19th and late 18th Centuries [Newcomb and McCann, 1987]. The earthquake history of this region is summarized in Figure 3.

[37] Chlieh et al. [2008] made a study of the seismic coupling of Sumatra based on coral uplift rates on offshore islands and interseismic GPS measurements. Their study area, from $2^{\circ} \mathrm{N}$ to $6^{\circ} \mathrm{S}$, is a $1000 \mathrm{~km}$ long zone beginning just south of the 2004 rupture. They found substantial alongstrike variations in coupling with correlation of high 


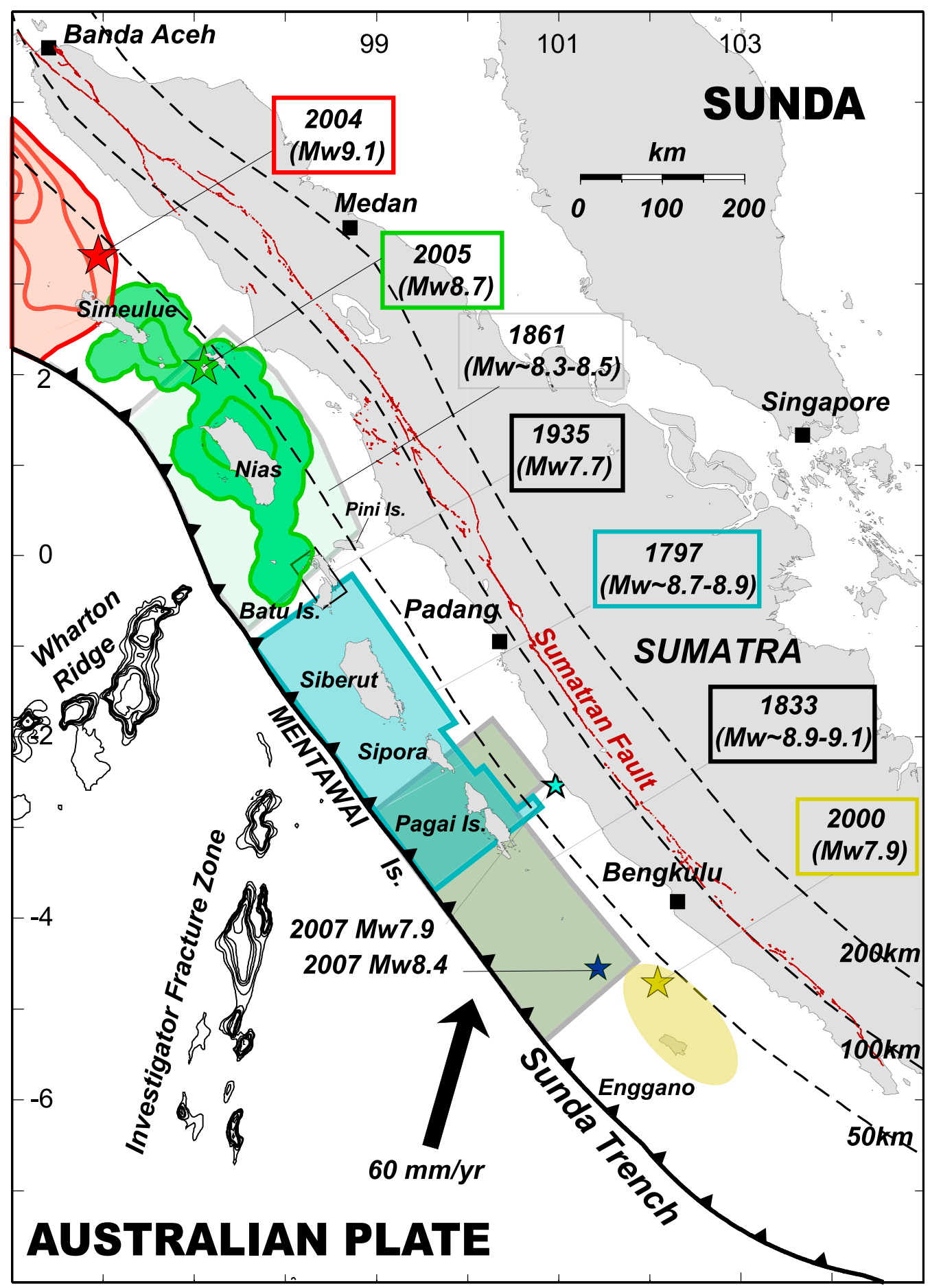

Figure 3. Recent seismic history of Sumatra from Chlieh et al. [2008].

coupling with offshore islands. For our purposes, we consider only their best fitting uniform coupling model, which has full coupling in a $150 \mathrm{~km}$ wide zone. We extrapolate this to $6^{\circ} \mathrm{N}$ to include the Sumatra portion of the 2004 rupture. This yields, for an average trench-normal plate motion rate of $45 \mathrm{~mm} / \mathrm{yr}, \dot{P}_{G}=10.8 \Phi$.

[38] Evidence from tsunami deposits in Thailand, the Andamans, and northern Sumatra [Jankaew et al., 2008; Meltzner et al., 2010; Monecke et al., 2008; Rajendran et al.,
2008], as well as uplifted corals on Simeulue Island [Meltzner et al., 2010], indicate that the most recent predecessor of the 2004 earthquake took place about 600 years B.P. For the 2004 earthquake we therefore use for the calculation of $\dot{P}_{S}, T=600 \mathrm{yrs}$ and its geodetic moment for the Sumatra sector: $4 \times 10^{22} \mathrm{Nm}$ [Subarya et al., 2006, model B]. For the 2005 and 2007 earthquakes and the 18th and 19th Century earthquakes (listed in Chlieh et al. [2008]) we use $T=300 \mathrm{yrs}$. These give us values of $\dot{P}_{S}$ in the range 5.4-9.0 $\Phi$ 
and corresponding $\chi_{\mathrm{S}}$ of $0.5-0.83$. The wide variation is due to the uncertainty of the magnitude of the pre-instrumental earthquakes.

[39] The finding that $\dot{P}_{S}$ is significantly less than $\dot{P}_{G}$ indicates that there has been an overall shortfall of seismicity in the Sumatra subduction zone during the current era. Chlieh et al. [2008], examining a wide range of coupling models, reached the same conclusion. Locally, for example, we see that the 2004 earthquake did not release all the accumulated strain in the Sumatra sector. Full coupling would have accumulated an average slip of $27 \mathrm{~m}$ over its 600 year inter-event time compared with an average slip in 2004 of about $17 \mathrm{~m}$ in that sector [Subarya et al., 2006, model B]. This conclusion was also reached by Meltzner et al. [2010], who noted that the previous cluster of events, from A.D. 1390-1455, produced considerably more uplift on Simuelue than did the 2004-2005 sequence. The Mentawai Islands segment to the south, which last ruptured in the great earthquakes of $1797\left(\mathrm{M}_{\mathrm{w}} 8.8\right)$ and $1833\left(\mathrm{M}_{\mathrm{w}} 9.0\right)$ [Natawidjaja et al., 2006, 2007], has been shown to rupture in clusters of great earthquake about every two hundred years over the past 700 years [Sieh et al., 2008]. It re-ruptured in the 2007 earthquake, which released only a fraction of the strain that had accumulated in that region since 1833 [Konca et al., 2008]. Sieh et al. [2008] argued thus that the 2007 earthquake was the start of an as yet incomplete rupture cycle for the Mentawai segment.

[40] The 2007 earthquake is another example showing that ruptures in the same location do not repeat the same rupture process or geometry. There is, however, in the Sumatra zone a strong correlation between the asperities of the great earthquakes of 2004-2007 with the zones of high coupling [Chlieh et al., 2008].

\subsection{Java}

[41] The Sunda arc fronting Java and the Lesser Sunda Islands is generally regarded as being seismically decoupled. It has no history of great subduction earthquakes [Newcomb and McCann, 1987] except possibly for an earthquake of 11/08/1818 listed in tsunami catalogs as an M 8.5 and having produced a tsunami in the Bali Sea [Rastogi, 2006]. There are also landslide scars observed on the eastern Sunda margin that could have been triggered by large earthquakes [Brune et al., 2009]. Of the rare thrust mechanism earthquakes that occur on this margin, two in 1994 and 2006, both $\mathrm{M}_{\mathrm{w}}$ 7.8, were of the tsunamigenic type, and, in the 1994 case, possibly occurred on at local instability patch associated with subduction of a seamount [Abercrombie et al., 2001; Ammon et al., 2006].

[42] However, in the light of recent experiences in Japan and Sumatra with giant subduction earthquakes following very long recurrence times, it is prudent to not accept such a lack of evidence as proof of seismic decoupling. Furthermore, the SC95 model predicts that the Sunda arc should be moderately coupled.

[43] Any conclusion regarding this area awaits GPS measurements that report the presence or absence of trenchnormal strain accumulation in the upper plate. Such studies are at an early stage. Abidin et al. [2009] report active motion on strike slip faults in western Java that would be consistent with a loaded upper plate. There are also preliminary results suggesting that west Java is coupled at about $70 \%$ [Hanifa et al., 2010].

\subsection{Hikurangi}

[44] The Hikurangi subduction system is the southern continuation of the Kermadec system along the east coast of the North Island of New Zealand. It terminates where it impinges upon the Chatham Rise, a continental segment, and from there the plate boundary continues as the Alpine fault transform system of the South Island. The Hikurangi system has not experienced any major megathrust earthquakes in the historic period.

[45] The northern part of the Hikurangi system parallels the Taupo volcanic zone, the continuation of the back arc spreading Lau Basin of the Kermadecs [Karig, 1970]. In this region the inversion of GPS data indicates that the plate interface is almost entirely decoupled [Wallace et al., 2004], except for a small area near the Raukumara peninsula that might be the result of subduction of a seamount. (Wallace et al. also artificially imposed the constraint that coupling is full at the surface - a feature that is not resolved by the data). South of Hawke's Bay, however, the Taupo zone terminates and the subduction interface gradually becomes more coupled further to the south. Slow slip events occur as shallow as $10 \mathrm{~km}$ in the northern part of the Hikurangi margin, and gradually deepen to $40 \mathrm{~km}$ in the southern part, tracking the deepening of the stability transition [Wallace and Beavan, 2010]. This transition to a compressional regime in the south is attributed to the buttressing effect of the Chatham Rise collision, which results in the transmission of compression across the subduction interface, the inhibition of back-arc spreading, and a rotation of the North Island block [Wallace et al., 2005].

[46] The decoupled nature of Hikurangi was predicted by SC95 model, but this latter end effect is outside the realm of that model.

\subsection{North Tonga}

[47] On 29 Sept. 2009 an $M_{w} 8.1$ outer rise normal faulting event triggered two $M_{w} 7.8$ thrust events at the northern end of the Tonga subduction zone [Beavan et al., 2010; Lay et al., 2010]. For this to have occurred those earthquakes must have been within conditionally stable regions with positive seismic flux accumulations. This confirms the contention of SC95 that this region is moderately coupled.

\subsection{Cascadia}

[48] This boundary between the Juan de Fuca and North American plates extends from southern British Columbia to northern California. Although it has been seismically quiescent during the historic period, paleoseismological evidence shows that it has been the site of repeated great subduction earthquakes [Atwater, 1987]. Geodetic data in the interseismic period show a $1100 \mathrm{~km}$ long coupled zone that narrows from north to south, with a fully locked zone of average width $60 \mathrm{~km}$, below which there is a transitional zone of partial coupling that decreases with depth [Hyndman and Wang, 1995; McCaffrey et al., 2000; Wang et al., 2003]. The fully locked zone ends at a depth of $30 \mathrm{~km}$, below which slip in the transition zone is accommodated aseismically by slow slip events (SSEs) [e.g., Rogers and Dragert, 2003]. The seismogenic width is thus taken to be $60 \mathrm{~km}$. This 
indicates, using $v_{p}=40 \mathrm{~mm} / \mathrm{yr}$, that $\boldsymbol{P}_{\boldsymbol{g}}=2.6 \Phi$, and $\chi_{\mathrm{G}}=1.0$.

[49] The most recent subduction zone earthquake along this coast occurred in 1700. Japanese tsunami records show that this earthquake probably ruptured the entire $1100 \mathrm{~km}$ length of this subduction zone, from Vancouver Island to northern California, in an event of $\mathrm{M}_{\mathrm{w}}$ 9.0-9.2 [Satake et al., 2003]. The record from submarine turbidite deposits suggests that such total-segment rupturing events have a recurrence time of $\sim 520$ years [Atwater and Hemphill-Haley, 1997; Goldfinger et al., 2003]. Coastal sites, however, paint a more complex picture, suggesting that events of different lengths have occurred, with often much shorter inter-event times [Kelsey et al., 2005]. In particular, shorter ruptures occur along the southern Cascadia margin at intervals of about 260 years [Goldfinger et al., 2008]. If we were to assume that all of $\boldsymbol{P}_{\boldsymbol{G}}$ was accounted for by total-segment rupturing events with a $520 \mathrm{yr}$ recurrence time, it would require those earthquakes to be $\mathrm{M}_{\mathrm{w}} 9.1\left(\mathrm{M}_{0}=5.4 \times 10^{22} \mathrm{Nm}\right)$, within the estimate range of Satake et al. If, on the other hand, the 520-year events were $M_{w} 9.0$, as favored be Satake et al., there would be room in the seismic cycle for one or more partial-sector rupturing events as suggested by the data of Kelsey et al. In either case the paleoseismic evidence strongly indicates full seismic coupling for this region.

\subsection{Central Aleutians}

[50] This study area is the $350 \mathrm{~km}$ long Andreanof Islands sector that was ruptured in the $\mathrm{M}_{\mathrm{w}} 8.0$ Andreanof earthquake of 1986 and, just to the west, an $\mathrm{M}_{\mathrm{w}} 7.9$ earthquake in 1996. Cross and Freymueller [2007] determined from GPS measurements that an $80 \mathrm{~km}$ wide zone corresponding to the rupture zones of those earthquakes is nearly fully coupled $\left(\chi_{\mathrm{G}}=0.96\right)$ at the $73 \mathrm{~mm} / \mathrm{yr}$ convergence rate. Just to the east, near Atka, coupling is low.

[51] This is a region of oblique convergence, and, like Sumatra, exhibits partitioning between arc parallel and arc normal motion [Cross and Freymueller, 2008; McCaffrey, 1992]. In the plate interface earthquakes, such as the one of $1986\left(\mathrm{M}_{\mathrm{o}}=1 \times 10^{21} \mathrm{Nm}\right)$ [Das and Kostrov, 1990], slip is in the arc-normal direction, so we use the arc-normal velocity, $61 \mathrm{~mm} / \mathrm{yr}$ [Cross and Freymueller, 2007], for our coupling calculations. This yields $\dot{P}_{G}=1.64 \Phi$.

[52] This region was previously ruptured by the western end of the $900 \mathrm{~km}$ long Mw8.6 earthquake of 1957. The sum of the moments of the two more recent earthquakes is $1.9 \times$ $10^{21} \mathrm{Nm}$, so that $P_{S}=4.75 \times 10^{10} \mathrm{~m}^{3}$. If we use $T=34$ years, the mean time since the 1957 event, we obtain $\dot{P}_{S}=1.4 \Phi$, which is less than the $\dot{P}_{G}$ value of 1.64. It had been previously thought that the time duration between 1957 and 1986 was insufficient to supply the seismic flux accumulation for the latter event. With that idea in mind, Boyd et al. [1995] argued, based on aftershock locations, that the 1986 rupture did not overlap the 1957 one, and Das and Henry [2003] proposed that the 1986 event occurred in a slip-deficit region of the 1957 rupture. Our calculations, however, show that there was sufficient time after 1957 to accumulate enough seismic flux to produce the earthquakes of 1986 and 1996, so that no such additional assumptions may be necessary.

[53] The area of major slip in the 1957 earthquake corresponded to this western coupled segment, where it averaged about $4 \mathrm{~m}$ [Johnson et al., 1994]. Dividing that by the convergence rate of $61 \mathrm{~mm} / \mathrm{yr}$ gives an estimate of its recharge time of $\sim 65$ years. This agrees with the previous activity of the region, which consisted of a series of large or great earthquakes of poorly known magnitude near the turn of the 20th Century [Sykes et al., 1981].

\subsection{Alaska}

[54] This region comprises the rupture area of the $\mathrm{M}_{\mathrm{w}} 9.2$, $\mathrm{M}_{\mathrm{o}} 8.2 \times 10^{22} \mathrm{Nm}$ [Kanamori, 1977] Alaska earthquake of 1964 that ruptured $800 \mathrm{~km}$ of the eastern Aleutian megathrust from Prince William Sound to just past Kodiak Island. The slip in this earthquake was concentrated in two asperities, the largest centered beneath Prince William Sound near the initiation end of the rupture and the second, smaller one, near its terminus beneath Kodiak [Christensen and Beck, 1994; Johnson et al., 1996].

[55] Savage et al. [1999, 1998], in 2D analyses of GPS data from the era 1993-1997, found that the region of the Prince William Sound asperity was fully coupled at $55 \mathrm{~mm} / \mathrm{yr}$ over a $W_{c}=280 \mathrm{~km}$ and over the Kodiak asperity with $W_{c}=$ $209 \mathrm{~km}$. Zweck et al. [2002] performed a 3D inversion of the 1992-1999 GPS data. They again found locked zones associated with the two asperities and also found a zone of very low coupling between them. Ohta et al. [2006], after correcting for post-seismic motion, found the highly locked zone associated with the PWS asperity to have a width of about $160 \mathrm{~km}$, narrower than the estimate of Savage et al. [1998]. We take the area of the strongly locked region beneath Prince William Sound to be about $160 \times 400 \mathrm{~km}$ [Ohta et al., 2006] and beneath Kodiak about $100 \times 150 \mathrm{~km}$ [Zweck et al., 2002]. Using a convergence rate of $55 \mathrm{~mm} / \mathrm{yr}$ and the sum of those areas yields a $\dot{P}_{G}=4.3 \Phi$. If we normalize that to the tectonic rate assuming full coupling over the entire $160 \times 800 \mathrm{~km}$ area, we obtain the estimate of $\chi_{\mathrm{G}}=$ 0.62 . This is a minimum estimate because we assumed coupling to be zero between the two stuck patches, which is undoubtedly an underestimate.

[56] Paleoseismic studies in the region of the 1964 earthquake have revealed 7 past earthquakes with an average recurrence time of 589 years [Carver and Plafker, 2008; Hutchinson and Crowell, 2007; Shennan et al., 2008]. The most recent of those to affect both PWS and Kodiak occurred at 800-900 (861 yr median age) and at 1400-1500 years BP. Those two earthquakes were larger than the 1964 event, rupturing an additional several hundred $\mathrm{km}$ farther to the east [Shennan et al., 2009]. If we assume a slip-predictable model [cf. Shimazaki and Nagata, 1980], we divide the $P_{S}$ for the 1964 earthquake, $2.1 \times 10^{12} \mathrm{~m}^{3}$, by 861 to get $\dot{P}_{S}=2.4 \Phi$, which indicates only partial seismic flux recovery in 1964 . For completeness, it would have been nice to include in this calculation an earthquake that occurred $\sim 500$ years BP [Carver and Plafker, 2008]. However, as that earthquake affected only the Kodiak sector, its magnitude must have been much less than the 1964 earthquake, hence its inclusion would not have greatly changed our conclusion. Alternately, if we assume a time-predictable model we must base our calculation on the size of the previous earthquake. Judging from it's length of $\sim 1000+\mathrm{km}$, we estimate that earthquake as $\sim \mathrm{M}_{\mathrm{w}} 9.4$, and distribute $80 \%$ of its seismic flux on our study area to obtain $\dot{P}_{S}=3.5 \Phi$, in much better agreement 
with our $\dot{P}_{G}$ estimate of $4.3 \Phi$, but still indicating a seismic slip deficit. These results are a consequence of the long recurrence interval in the latest cycle, which is at the long end of the spectrum of the cycles documented by Carver and Plafker. If, on the other hand, we look at the penultimate cycle, which had a recurrence interval of $\sim 600$ years, and use the same time-predictable assumptions, we obtain $\dot{P}_{S}=5.0$, greater than our $\dot{P}_{G}$ estimate. There is no requirement for this seismic flux rate balance to apply to a single seismic cycle. It is only over the long-term, averaged over many cycles, that we expect to see the equilibrium between $\dot{P}_{G}$ and $\dot{P}_{S}$. Overall, this region seems to be in equilibrium.

\subsection{Eastern Aleutians}

[57] This region comprises a 600 long segment off the Alaskan Peninsula from Kodiak to Sanak Island. It exhibits great variability in coupling [Fournier and Freymueller, 2007], and so we further subdivide it for discussion.

[58] Semidi Islands: This region, just west of Kodiak, was last ruptured in the $\mathrm{M}_{\mathrm{w}} 8.2$ earthquake of 1938. Fletcher et al. [2001] performed a 2D inversion of GPS data to obtain, compared with a $59 \mathrm{~mm} / \mathrm{yr}$ trench- normal convergence velocity, $80 \%$ coupling on a $180 \mathrm{~km}$ wide zone. Fournier and Freymueller [2007] further subdivided this segment, finding $90 \%$ coupling in its eastern half and $70 \%$ in the western portion and refined the width of the coupled zone to $160 \mathrm{~km}$ (estimating that $W_{c}$ occurred on an $8^{\circ}$ dipping plane from 5 to $28 \mathrm{~km}$ ). The 1938 rupture zone was about $250 \mathrm{~km}$ long, so $A_{c}=4.0 \times 10^{10}$ and $\dot{P}_{G}=1.9 \Phi$.

[59] The 1938 rupture was preceded by similar earthquakes in 1788,1847 , and 1880 , indicating a recurrence time of 49 years [Nishenko, 1991]. The 1938 earthquake had a moment of $2.1-5.0 \times 10^{21} \mathrm{Nm}$ [Abe, 1979; Brune and Engen, 1969; Estabrook et al., 1994]. This provides an estimate of $\dot{P}_{S}=1.1-2.5 \Phi$. This region seems to be overdue for a great earthquake, but the uncertainties in this are great. Nishenko [1991] also mentioned that it was questionable if the 1880 earthquake ruptured the entire segment. If this earthquake were deleted it would give a $T=75$ years and hence a proportionally smaller $\dot{P}_{S}$. If this estimate was adopted it would contradictorily argue both that another earthquake was less imminent (from the greater $T$ ) and more imminent (from the lesser $\dot{P}_{S}$ ). Hence we do not favor this latter interpretation.

[60] Shumagin Islands: This region, just to the west of the 1938 rupture zone, has had no great earthquake in the instrumental period and was consequently identified as a seismic gap by Sykes [1971]. It has since been a source of controversy as to whether or not it is capable of producing a great earthquake. This question has been resolved with the analysis of GPS data, which indicate low coupling [Fournier and Freymueller, 2007; Freymueller and Beavan, 1999]. Fournier and Freymueller [2007] found that the $125 \mathrm{~km}$ long Shumagin sector had $\dot{P}_{G}=0.2 \Phi$ and $\chi_{\mathrm{G}}=0.3$. To the west, in the region of Sanak Island, they found full decoupling. Thus there is a strong gradient in coupling from the Samedi Islands to Sanak.

[61] The record of large historic earthquakes suggests that there is a gradient of coupling even within the narrow $125 \mathrm{~km}$ long Shumagin zone defined by Fournier and
Freymueller [2007]. The eastern half of that zone has been ruptured three times in the historic record, in earthquakes of 1788, 1847, and 1917, whereas the western half has been ruptured only once, in the $\mathrm{M}_{\mathrm{w}} 7.5$ earthquake of 1948 [Davies et al., 1981; Estabrook and Boyd, 1992]. The temporal spacing of the three eastern events leads to the oft-quoted recurrence time of 65 years [e.g., Nishenko, 1991]. The 1917 earthquake was $M_{w} 7.4, M_{0} 1.7 \times$ $10^{20} \mathrm{Nm}$ [Estabrook and Boyd, 1992]. These two estimates yield $\dot{P}_{S}=0.06 \Phi$, clearly deficient as compared to the geodetic result. (Using the same assumptions and smaller values of $\mu$ and $A_{c}$, Zheng et al. [1996] obtained $\chi_{\mathrm{s}}=$ 0.15.) The problem with those estimates is that they implicitly assume that all three eastern earthquakes were the same size of the 1917 event. The 1788 and 1847 earthquakes, however, were great earthquakes, having ruptured, in addition to the 1917 sector, all of the 1938 rupture zone and possibly extended as far to the east as Kodiak. Hence the slip they would have provided to the 1917 sector would have been much greater than that of the 1917 earthquake. Because it is not possible to estimate the contributions of those earlier earthquakes, we consider this estimate of $\dot{P}_{S}$ to be unreliable and mark it so (n.r.) in the table.

\subsection{Chile}

[62] The seismic history of Chile is shown in Figure 4. We limit our analysis to the labeled regions bounded by the dashed lines, for which there are determinations of seismic coupling from GPS measurements of the deformation of the upper plate.

[63] Central Chile: For this region we take as our exemplary locality the region between 34 and $38^{\circ} \mathrm{S}$ (Figure 4) which was a seismic gap that was filled by the $M_{w} 8.8$ Maule earthquake of 2010 [Vigny et al., 2011]. The previous earthquake to have ruptured this region was the one witnessed by Darwin and Fitzroy in 1835 . That $\mathrm{M}_{\mathrm{w}} 8.6$ event appears to have been part of a cycle-defining cluster that included an earthquake of 1822 just to the north and the $\mathrm{M}_{\mathrm{w}}$ 8.91837 earthquake that ruptured to the south and continued into the zone of the 1960 earthquake. Using this $185 \mathrm{yr}$ recurrence time and the moment of the 2010 Maule earthquake provides a $\dot{P}_{S}$ of $2.9 \Phi$. Interseismic strain accumulation measurements prior to 2010 found full coupling at 68 $\mathrm{mm} / \mathrm{yr}$ over an area of $60 \times 10^{9} \mathrm{~m}^{2}$ [Ruegg et al., 2009]. From this we calculate $\dot{P}_{G}=4.1 \Phi$. These estimates yield the values of $\chi_{S}=0.7$ and $\chi_{G}=1.0$. It appears that the Maule earthquake may not have fully released the strain accumulated in the latest seismic cycle.

[64] Southern Chile: This is the region of the great Valdivia earthquake of $1960\left(37-45^{\circ} \mathrm{S}\right)$. This earthquake consisted of a $\mathrm{M}_{\mathrm{w}} 9.5$ main shock with a slow precursor of almost the same size [Cifuentes and Silver, 1989; Kanamori, 1977; Kanamori and Cipar, 1974]. The geodetic moment was much less [Plafker and Savage, 1970], and was estimated to be $9.5 \times 10^{22} \mathrm{~N}-\mathrm{m}$ [Barrientos and Ward, 1990]. The discrepancy between these estimates led to the conclusion that much of the seismically determined moment resulted from slow slip below the seismogenic part of the fault [Kanamori and Cipar, 1974; Cifuentes and Silver, 1989], some of which was detected by Barrientos and 


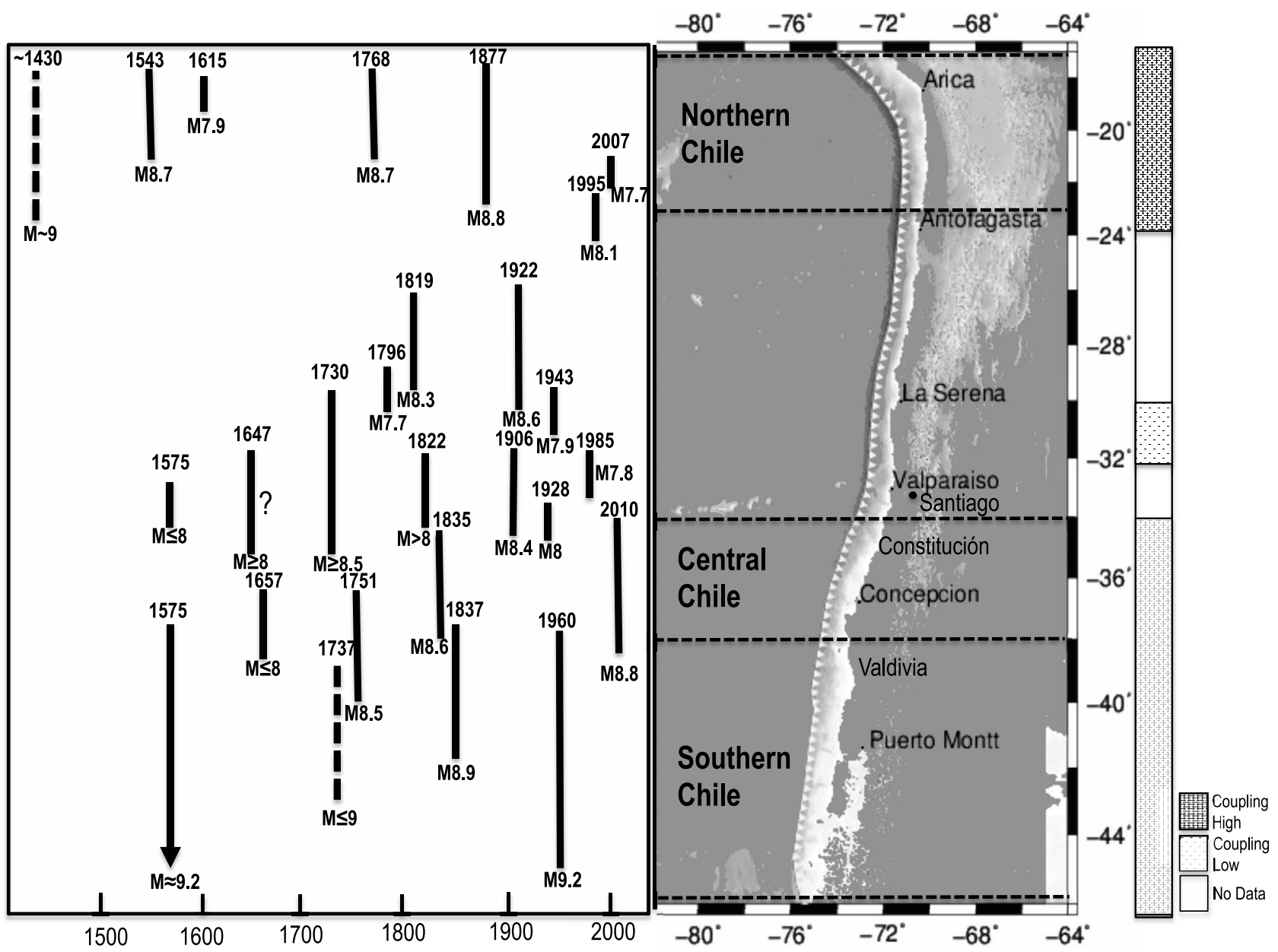

Figure 4. The earthquake history and coupling of Chile. See text for sources of coupling data.

Ward [1990] as far as $400 \mathrm{~km}$ downdip. Because we study only the seismogenic portion of the interface, for our calculations we use the geodetic estimates of the moment. Lorenzo-Martin et al. [2006] found, from GPS measurements, that $\chi_{\mathrm{G}}=0.96$ for $A_{c}=110 \times 10^{9} \mathrm{~m}^{2}$ and an assumed subduction velocity of $69 \mathrm{~mm} / \mathrm{yr}$, yielding $\dot{P}_{G}=7.3 \Phi$.

[65] The only known preceding earthquake of size similar to the 1960 event was one that occurred in 1575 [Cisternas et al., 2005]. Using that $385 \mathrm{yr}$ recurrence time yields $\dot{P}_{S}=$ $6.2 \Phi$, for a $\chi_{\mathrm{S}}=0.8$. If we include in that period the 1837 earthquake, estimated to have been about half the size of $1960[\mathrm{Abe}, 1979]$, we get $\dot{P}_{S}=9.3 \Phi$, larger than $\dot{P}_{G}$ (this is an overestimate because a goodly portion of the 1837 earthquake occurred in the Central Chile segment). The tsunami record of this region indicates great tsunami-generating events every 285 years on average [Cisternas et al., 2005]. This consists of the less frequent 1960-type events that rupture the entire $850 \mathrm{~km}$ length of this segment and smaller earthquakes like that of 1837 that rupture portions of it.

[66] Northern Chile: This region, from 18 to $23^{\circ} \mathrm{S}$, is a $450 \mathrm{~km}$ long seismic gap that last ruptured in the Iquique earthquake of 1877 , with a magnitude estimated at $\mathrm{M}_{\mathrm{w}}$ 8.8-9.0 [Abe, 1979; Bejar-Pizarro et al., 2010; Comte and Pardo, 1991; Kausel and Campos, 1992]. Chlieh et al. [2004] studied this area with GPS and INSAR and concluded it was fully coupled on a $20^{\circ}$ dipping surface down to $35 \mathrm{~km}$ depth, below which the coupling linearly tapered to zero at $55 \mathrm{~km}$. By the same reasoning as discussed in the Cascadia case, we take the fully locked region to be the seismogenic area. This boundary seems to have been defined by the $M_{w} 7.7$ Tocopilla earthquake of 2007, in which its region of maximum slip was concentrated around $35 \mathrm{~km}$, with some slip, possibly post-seismic, extending to 50 $\mathrm{km}$ depth [Bejar-Pizarro et al., 2010]. Hence with this assumption $\chi_{\mathrm{G}}=1$ and with $v_{p}=79 \mathrm{~mm} / \mathrm{yr}$ on a $102 \times 450$ $\mathrm{km}$ surface, $\dot{P}_{G}=3.6 \Phi$. Vargas et al. [2005] identified sector-rupturing earthquakes prior to 1877 in 1768,1543 , and 1430, which indicate an average $T$ of 149 years [Comte and Pardo, 1991; Nishenko, 1985]. Assuming $\mathrm{M}_{\mathrm{w}} 8.8$ for these earthquakes and this value of $T$ yields $\dot{P}_{S}=3.4 \Phi$ and $\chi_{\mathrm{S}}=$ 0.94 .

\subsection{Central and Southern Peru}

[67] The earthquake history and coupling of this region are shown in Figure 5 (modified after Dorbath et al. [1990]). The coupling of the northern two-thirds of this region was determined by Perfettini et al. [2010]. They found three zones of high coupling, shown in Figure 5. A narrow zone of low coupling separates the northern two. The southern two are separated by a much wider zone of low coupling that 


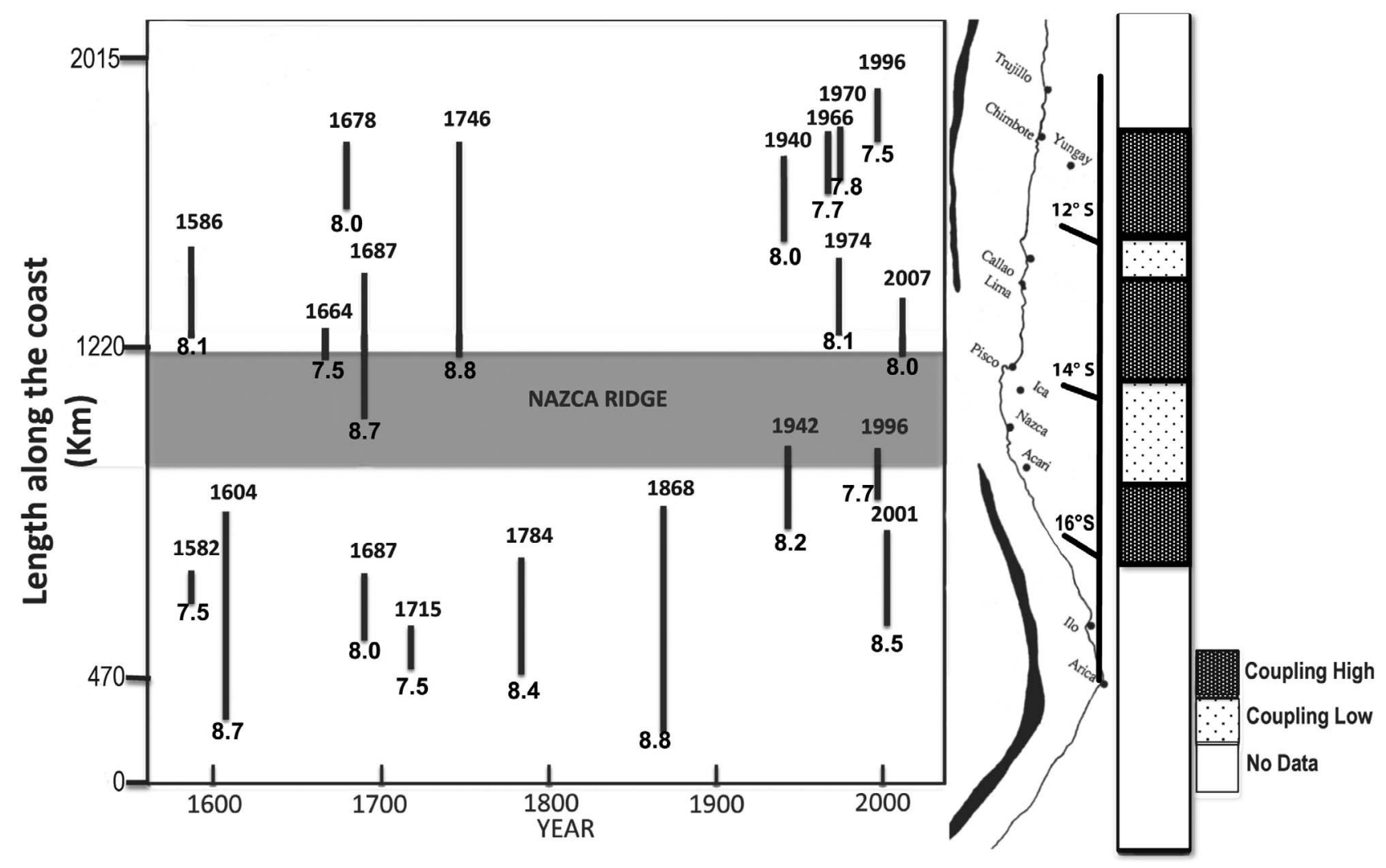

Figure 5. The earthquake history and seismic coupling of central and southern Peru (modified from Dorbath et al. [1990] with additions). Coupling from Perfettini et al. [2010].

corresponds to the area of impingement of the Nazca ridge, which also manifests itself by the disappearance of the trench. As can be seen in Figure 5, the Nazca ridge acts as a profound barrier to earthquakes that, whether propagating from the north or the south, terminate within it, a point noted earlier by Kelleher and McCann [1976]. The Nazca ridge thus divides this region into two parts, which we discuss separately.

[68] Central Peru. The average coupling coefficient for the region from 11 to $16^{\circ} \mathrm{S}$ was determined by Perfettini et al. [2010] to be in the range 0.41-0.62. If we take the region north of the Nazca ridge, we get $\chi_{\mathrm{G}} \sim 0.75$, from which we obtain $\dot{P}_{G}=2.9 \Phi$. The earthquake history (Figure 5) shows a cluster of great earthquakes from 1678 to 1746. We surmise that this cluster, which together sums to $\mathrm{M}_{\mathrm{w}} 9.0$, must have ruptured this plate boundary segment in its entirety and hence marks the beginning of a seismic cycle which we take as starting at their midpoint time, 1720. This episode is followed by a long quiescent period that ends with a series of $M_{w}>8$ earthquakes beginning in 1940 and continues to the present. We consider this second burst of activity to mark the advent of the next seismic cycle and suppose its midpoint to be, say, 1990. Adopting the timepredictable model, we divide the sum of the seismic flux of the first cluster, $8.8 \times 10^{11} \mathrm{~m}^{3}$, by the cycle period, 270 years, to get $\dot{P}_{S}=3.2 \Phi$, in good agreement with the estimate of $\dot{P}_{G}$. The summed seismic flux from the activity since 1940 is $2.2 \times 10^{11} \mathrm{~m}^{3}$, so, depending on whether we assume the seismic rate of $3.2 \Phi$ or the geodetic rate of
$2.9 \Phi$, a flux of 6.6 to $5.6 \times 10^{11} \mathrm{~m}^{3}$ is needed to complete this cycle. This is equivalent to an $\mathrm{M}_{\mathrm{w}} 8.9$ or 8.8 earthquake, respectively. This is simply a statement regarding the energy balance. It should not be taken as implying that such an earthquake is imminent.

[69] Southern Peru. This is the sector of Peru south of the Nazca ridge. We have geodetic measurement of seismic coupling only for the northern part of this area. We calculate a value of $\dot{P}_{T}=3.9 \Phi$ by using the interface geometry of Hergert and Heidback [2006] and $v_{p}=62 \mathrm{~mm} / \mathrm{yr}$. The earthquake history of this region (Figure 5) does not seem to cluster into discernable seismic cycles. So for this region we use the default method for estimating $\dot{P}_{S}$ : summing all the earthquakes to get $P_{S}=1.17 \times 10^{12} \mathrm{~m}^{3}$ and dividing by the observation period, 400 years. The yields $\dot{P}_{S}=2.9 \Phi$, and hence $\chi_{\mathrm{s}}=0.75$.

\subsection{Colombia-Ecuador}

[70] A $500 \mathrm{~km}$ section of this subduction zone was ruptured in the $M_{w} 8.8$ earthquake of 1906 . The same sector was subsequently re-ruptured in a series of smaller and shorter earthquakes: $M_{S} 7.9$ (1942), $M_{S} 7.8$ (1958), and $M_{S} 7.7$ (1979). The sum of the moment of those three earthquakes came to about $20 \%$ of that of the 1906 earthquake [Kanamori and McNally, 1982]. (This may be partially accounted for by the nature of the scaling laws. Because mean slip is proportional to length, the sum of the moment of 3 earthquakes $1 / 3$ the length of the larger would be $1 / 3$ that of the larger.) 
[71] White et al. [2003] evaluated campaign GPS data from the period 1991-1998 to conclude that this plate interface was $50 \%$ coupled. Adopting their model of coupling to $30 \mathrm{~km}$ depth, we have $W_{C}=90 \mathrm{~km}$, and with $v_{p}=$ $58 \mathrm{~mm} / \mathrm{yr}$ we obtain $\dot{P}_{G}=1.3 \Phi$. Combining that finding with the moment of the 1906 earthquake, $2 \times 10^{22} \mathrm{~N}-\mathrm{m}$, indicates that such an earthquake should have a recurrence time of about 380 years. The pre-1906 seismic history of this region is too incomplete to assess this possibility [Nishenko, 1991]. The 1906 earthquake attests to the high coupling of this region, but the lack of data prevent us from quantifying that property.

\subsection{Central America}

[72] Seismic coupling along the $850 \mathrm{~km}$ long sector encompassing the Salvadoran, Nicaraguan, and Costa Rican coasts has been analyzed from GPS observations [CorreaMora et al., 2009; LaFemina et al., 2009; Norabena et al., 2004]. This is an area of marked along strike variability in coupling. In Costa Rica the coupling is moderate to high, particularly beneath the Nicoya and Osa Peninsulas. In contrast, GPS data indicate that coupling is very low off Nicaragua and El Salvador. GPS data for that region is dominated by trench parallel velocities, even though the plate convergence is trench-normal. The $1992 \mathrm{M}_{\mathrm{w}} 7.6$ Nicaragua earthquake, a tsunami earthquake that ruptured the subduction interface for about $250 \mathrm{~km}$ along strike at depths shallower than $20 \mathrm{~km}$ [Ide et al., 1993; Satake, 1994] indicates that this narrow strip must be coupled at about $70 \%$ [Correa-Mora et al., 2009]. Summing the contribution from this area and the Nicoya and Osa peninsulas gives $\dot{P}_{G}=1.7$ $\Phi$, which, when compared to $\dot{P}_{T}=7.6 \Phi$, yields $\chi_{\mathrm{G}}=0.20$. The summed seismic moments from Pacheco et al. [1993] give $\dot{P}_{S}=0.74 \Phi$, for $\chi_{\mathrm{S}}=0.10$.

[73] The very low coupling of the Nicaragua-Salvador sector, which is largely responsible for the low overall coupling coefficient for this region, is quite anomalous and at odds with the SC95 model. LaFemina et al. [2009] proposed that the Costa Rica segment is a collisional zone in which the Cocos Ridge acts as an indenter against the Caribbean Plate. They would then explain the trench parallel velocities in Nicaragua as 'escape' tectonics. This same action could, by pushing back the upper plate, reduce the interface normal stress along the adjacent subduction interfaces in Nicaragua and Salvador and drive them into the conditionally stable field, thereby reducing their coupling.

\subsection{Mexico}

[74] The region we study is a $625 \mathrm{~km}$ long sector of Oaxaca and Guerrero that runs from the SE edge of the $M_{w}$ 7.81978 Oaxaca earthquake to the SE edge of the $1985 \mathrm{Mw}$ 8.1 Michoacan earthquake, -96.7 to $-102^{\circ} \mathrm{E}$. The subduction interface in this region has an unusual shape. From the trench it dips at about $20^{\circ}$ to about $70 \mathrm{~km}$ from the trench, then has a steep section to about $35 \mathrm{~km}$ depth at which point it becomes near horizontal [Franco et al., 2005]. The seismogenic zone is the deeper portion of the initial, shallow dipping surface, which is highly coupled. The steeply dipping and the horizontal portions are partially coupled over a width of $\sim 140 \mathrm{~km}$. Slip on those latter two sections is accommodated by SSEs, including a very large one, called a silent earthquake, that occurred in 2001-2002 and had an equivalent moment magnitude $\mathrm{M}_{\mathrm{w}} 7.5$ [Franco et al., 2005; Kostoglodov et al., 2003; Walpersdorf et al., 2011]. The seismogenic zone is very narrow in this region, and strongly segmented, so that plate boundary rupturing earthquakes are unusually small, of magnitude $\leq \mathrm{M}$ 8.0. There is a strong gradient in $v_{p}$ in this region, from $53 \mathrm{~mm} / \mathrm{yr}$ in the NW to $64 \mathrm{~mm} / \mathrm{yr}$ in the SE. This would result in a similar variation of recurrence time, which is probably why this region ruptures in rather short segments.

[75] We divide this region into two parts. The first part is the rupture zone of the $\mathrm{M}_{\mathrm{S}} 7.81978$ Oaxaca earthquake, which was the subject of a focused study by Correa-Mora et al. [2008]. From inversion of GPS data they found a fully coupled region $75 \mathrm{~km}$ long and $60 \mathrm{~km}$ wide. Using $v_{p}=$ $64 \mathrm{~mm} / \mathrm{yr}$ gives $\dot{P}_{G}=0.29 \Phi$. Earthquakes previously ruptured this area in $1870\left(\mathrm{M}_{\mathrm{S}} 7.9\right)$ and 17 June $1928\left(\mathrm{M}_{\mathrm{S}} 8.0\right)$, indicating a recurrence time of $54 \pm 4$ years [Nishenko, 1991]. Dividing the seismic flux of the 1978 earthquake by this gives $\dot{P}_{S}=0.29 \Phi$, in agreement with the geodetic estimate. Thus this area is fully coupled by both measures. It has a very simple coupling structure: a single isolated stuck patch. This results in a simple pattern of seismicity: periodically repeating earthquakes of very similar size.

[76] The $550 \mathrm{~km}$ long sector northwest of the Oaxaca rupture zone has a geodetically determined coupling coefficient of 0.9 on a $35 \mathrm{~km}$ wide strip [Franco et al., 2005]. Using an average $v_{p}$ of $57 \mathrm{~mm} / \mathrm{yr}$ for this sector, we obtain $\dot{P}_{G}=1.0 \Phi$. If we update the list in Nishenko [1991] and sum the seismic flux of all earthquakes $M_{S} \geq 7.4$ from 1890 to the present, and, using the default method, divide by 120 years, we obtain $\dot{P}_{S}=1.5 \Phi$. The plate rupturing earthquakes are relatively small and hence frequent in this region, with recurrence times in the range 50-70 years Nishenko [1991], significantly smaller than $t_{o}$, so the default method is particularly robust in this case. The discrepancy with the geodetic estimate is most likely a result of the poor GPS resolution of the updip extent of coupling, which affects the estimate of $W_{c}$. If we used, alternatively, the average width of the aftershock zones of the plate rupturing earthquakes, $50 \mathrm{~km}$, for $W_{c}$ we get $\dot{P}_{G}=1.4 \Phi$, in much better agreement with $\dot{P}_{S}$. We report this latter estimate as our favored one.

\section{Discussion}

[77] In the previous section we presented vignettes of the seismic coupling of many of the world's subduction zones. We summarized determinations of seismic flux accumulation rates derived from GPS studies of upper plate deformation and provided new estimates of seismic flux release rates from the seismic histories of the various regions.

\subsection{Comparison of $\dot{\boldsymbol{P}}_{S}$ and $\dot{\boldsymbol{P}}_{G}$}

[78] We expect the seismic flux accumulation rate $\dot{P}_{G}$ to equal the release rate $\dot{P}_{S}$ over some sufficiently long time scale, which needn't be a single seismic cycle. For example, in the case of the 1964 Alaska earthquake segment, we found $\dot{P}_{S}<\dot{P}_{G}$ in the most recent seismic cycle but the opposite to be true in the previous one.

[79] Nevertheless, it is useful to compare the two estimates. The geodetic measurement has more well-defined 


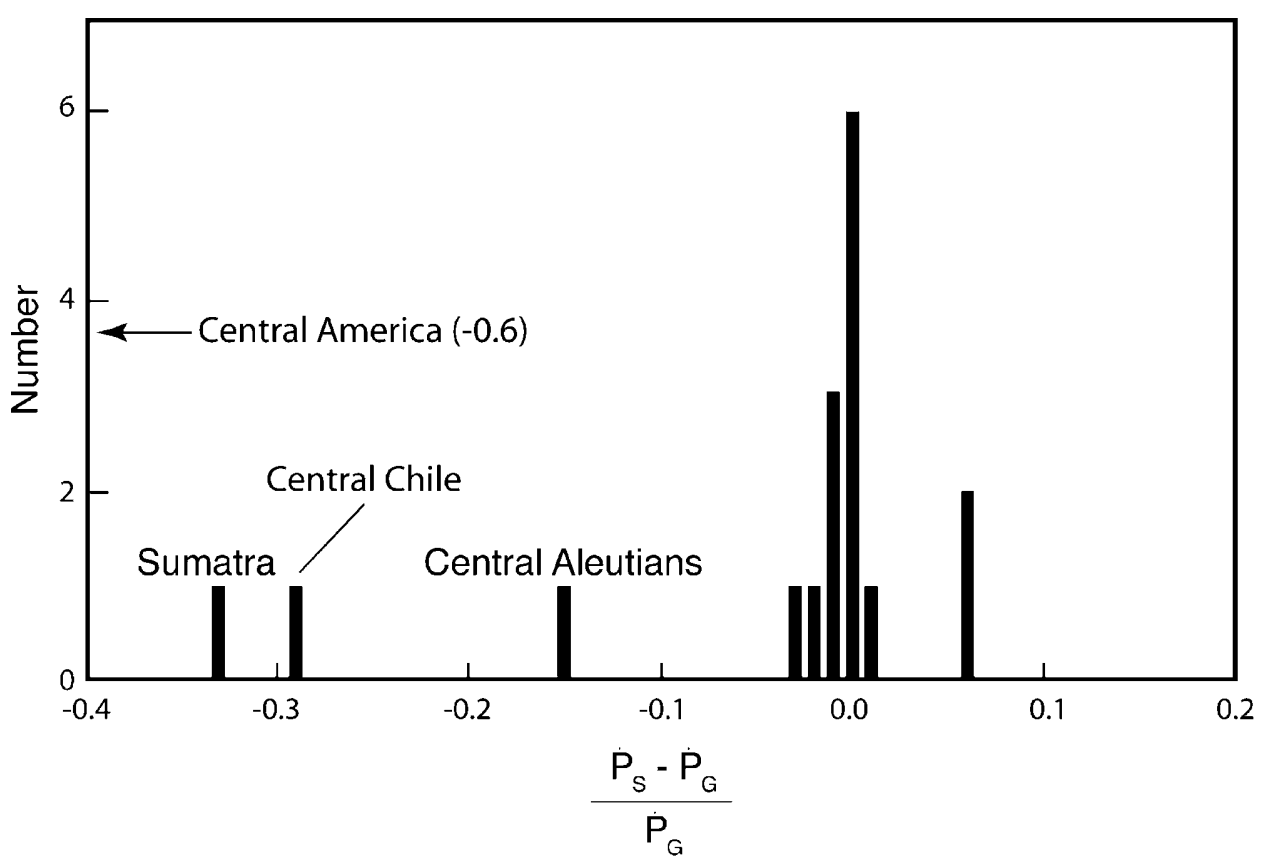

Figure 6. Histogram of $\left(\dot{P}_{S}-\dot{P}_{G}\right) / \dot{P}_{G}$ comparing the geodetic and seismic estimates of coupling. When there is a range in either estimate, as simple average is used.

uncertainties than the seismological determination, so comparing the one with the other allows for the assessment of the seismological estimate. In Figure 6 we show a histogram of $\left(\dot{P}_{S}-\dot{P}_{G}\right) / \dot{P}_{G}$. What is shown is that, with a few notable outliers, the two estimates agree to within $10 \%$. This somewhat surprising concordance between the estimates results from our improved methods of estimating $\dot{P}_{S}$.

[80] The method we used for determining $\dot{P}_{S}$ varied according to the nature of the seismic data set in each region we studied. In the studies of the previous era [Peterson and Seno, 1984; Pacheco et al., 1993] data was limited to the instrumental period, and the estimate of $\dot{P}_{S}$ was made by summing seismic moments over that period and dividing by the length of the observational period $t_{o}$. In the present study we were forced to use that default method in only a few cases, such as southern Peru and Mexico. In those cases $t_{o}$ was large with respect to the average recurrence time $T$ so that this method was particularly robust. In all other cases, we were able to estimate the recurrence time $T$ for the largest earthquakes from either historic or paleoseismological data. In a few cases, for example Hokkaido and Cascadia, we used paleoseismic evidence to introduce into our analysis earthquakes unknown in the historic or instrumental record. We learned to do this from the 2011 Tohoku earthquake, the like of which had been lurking in the paleoseismic and historic record but which had not been recognized, prior to its occurrence, by most earth scientists, earthquake engineers, or those involved in public policy.

[81] It was, of course, an advantage that we had a fiducial mark, $\dot{P}_{G}$ as a target for our estimates of $\dot{P}_{S}$. This allowed us to sort between difference recurrence models, for example, in our search for our favored models of $\dot{P}_{S}$ but did not require us to adopt any unreasonable models.
[82] The 2011 Tohoku-oki earthquake presents a potential difficulty, however. Its unprecedented large slip at very shallow depths was not anticipated by any of the three interplate coupling models derived from GPS data [Hashimoto et al., 2009; Suwa et al., 2006; Loveless and Meade, 2010]. This is probably largely because such inversions from land-based data have very poor resolution so far from shore. This is a problem because if such behavior is more common than previously assumed it may result in underestimations of $\dot{P}_{G}$ and hence seismic hazard in some regions.

\subsection{Comparison With the SC95 Model}

[83] The SC95 model [Scholz and Campos, 1995], as outlined earlier, sought to explain variations of coupling among subduction zones by variations of the normal force, $\Delta F_{n}$ supplied to the plate interface by plate tectonic forces. This parameter was calculated as

$$
\Delta F_{N}=F_{S A} \sin \phi+F_{S U} \cos \phi
$$

where $\phi$ is the dip of the subduction interface. The trench suction force $F_{S U}$ is a function of slab length and age of the subducting plate and the sea anchor force $F_{S A}$ is a function of upper plate velocity and slab length.

[84] Figure 7 shows the coupling coefficients plotted versus that parameter. To get a feeling for the horizontal axis, note that for a typical $W_{c}$ value of $100 \mathrm{~km}$, a change in $\Delta F_{n}$ of $1 \times 10^{12} \mathrm{Nm}^{-1}$ is equivalent to a mean change of normal stress of $10 \mathrm{MPa}$, so that the entire scale range is $70 \mathrm{MPa}$. These changes are relative to a reference state, and the absolute value of normal stress is not known.

[85] The curves show bounds on the prediction of the model, which was calibrated with the Izu-Bonin-Marianas 


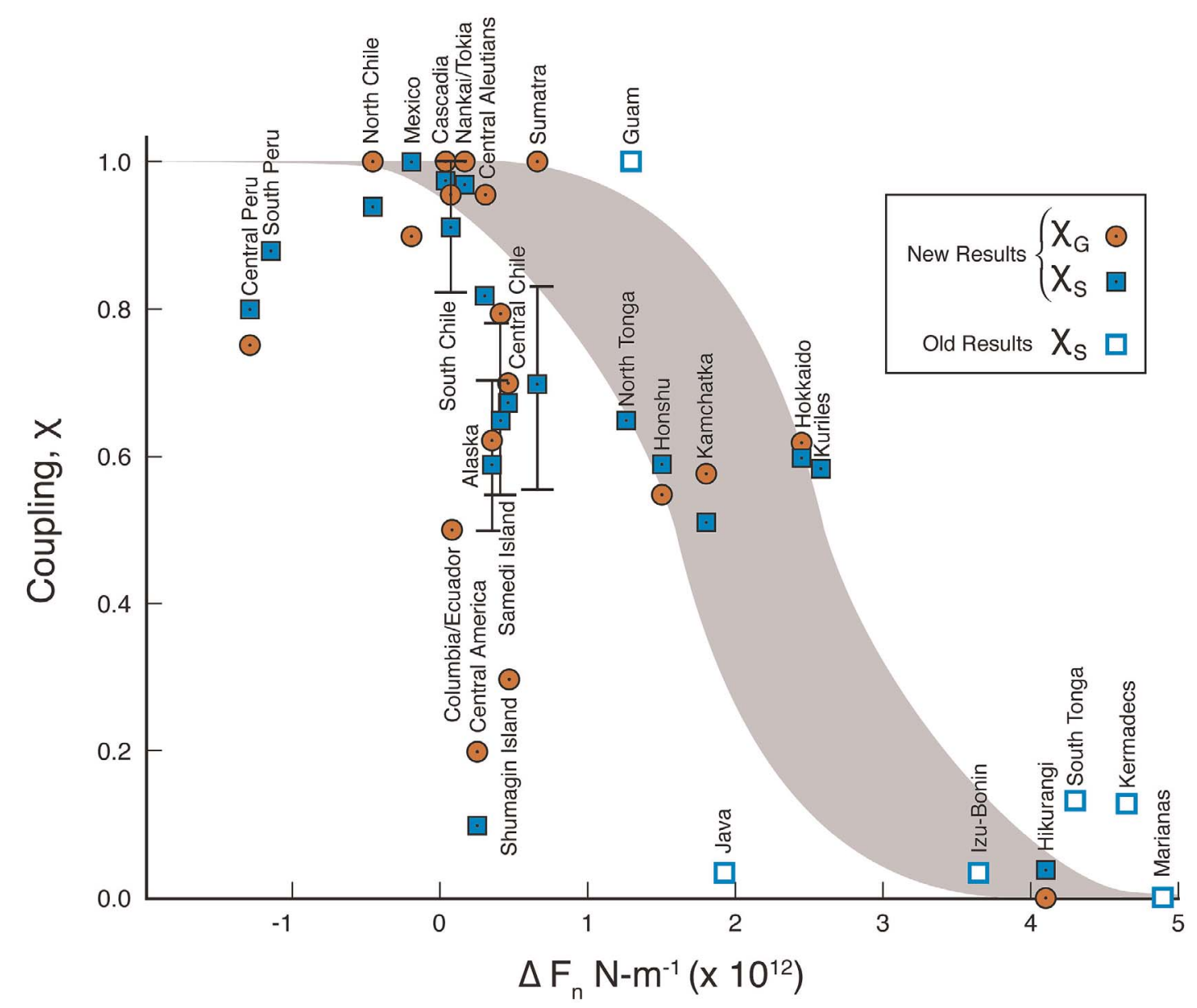

Figure 7. The various estimates of seismic coupling coefficient plotted versus $\Delta \mathrm{F}_{\mathrm{n}}$, the reduction of normal force on the subduction interface relative to a reference state. The latter were calculated from plate tectonic forces [Scholz and Campos, 1995]. The curves delineating gray areas were obtained, independently of the data shown, from calibration with the Izu-Bonin/Marianas system.

system, which exhibits a transition from coupled (Guam) to decoupled (Marianas) in a system where many of the plate tectonic variables, such as the age of the subducting plate, remain constant.

[86] Positive values of $\Delta F_{n}$ indicate reductions of the normal force relative to a reference state. The data divide themselves into three groups, in very good agreement with the model. Group A (Izu-Bonin, Marianas, Kermadec, Hikurangi and South Tonga) contains subduction zones at the low normal force end of the spectrum and are decoupled. Group B (Kamchatcka, Honshu, Kuriles, Hokkaido, and N. Tonga) is an intermediate group that shows partial coupling. Group C (All of Chile, Central and South Peru, most of the Aleutians and Alaska, Cascadia, Sumatra, Nankaido, Guam and Mexico) contains zones in the high normal stress regime and are highly coupled. Note that the transition region as defined by the curves was determined independently of these data.

[87] The agreement between the observations and the model has been considerably improved over the first comparison in SC95, when there were no geodetic estimates and the seismological ones were based on what we now call the default method and hence were much poorer. In particular, several regions that were then outliers, on the low coupling side, Honshu and Sumatra, are now, because of intervening giant earthquakes, found to be in much better agreement with the model. The model also predicted, with little supportive data at the time, low coupling for Hikurangi and high coupling for the central Kuriles and Cascadia, all of which have now been confirmed.

[88] It has been noted that the 2004 Sumatra-Andaman earthquake as well as other more recent data conflict with the Ruff and Kanamori [1980, 1983] proposal for seismic coupling [Stein and Okal, 2007]. The occurrence of the 2011 Tohoku-oki earthquake also disagreed with that model. The main problem with the Ruff and Kanamori model is that it only considers parameters that go into the $F_{S U}$ term in equation (7), and neglects the $F_{S A}$ term, which is of the same magnitude. Neither of those giant earthquakes, however, conflicted with the SC 95 model. Prior to these earthquakes both Sumatra and Honshu were outliers in that their seismic coupling coefficients were much smaller than predicted by SC95, so their occurrence serves to validate the model.

[89] The strong agreement that now is shown between the theory and observations of seismic coupling belies the contrarian view of McCaffrey [2008] that all subduction zones are equally capable of producing magnitude 9 earthquakes. There are two classes of subduction zones where we would 
argue that this is not possible: the uncoupled arcs, such as the Marianas or the northern part of the Hikurangi, and those arcs, that, although coupled, are, like Mexico, so narrow and segmented that they haven't a large enough $A_{c}$ to support such a giant event. Note that the seismic coupling coefficient, as we define it, does not predict the largest possible earthquake in a given subduction zone. That is a function of other factors, such as the degree of segmentation and the total coupled area $A_{c}$ available to accommodate a rupture.

[90] There remain several significant outliers, in particular: Java, Central America, and the Shumagins. These and other departures from model expectations will be discussed in the next section.

\subsection{Along-Strike Variations in Coupling: Anomalous Decoupled Regions}

[91] The SC95 model appears to explain to first order the variation of seismic coupling of subduction zones. The geodetic observations also show, when they are sufficiently dense to resolve such features, that coupling may be quite variable within individual subduction zones. The basic theory, as outlined in Section 2.2, predicts heterogeneity in coupling simply from the heterogeneity in the topography of the contacting surfaces. This may explain some of the variability observed.

[92] The SC95 model is based on a 2D analysis and therefore does not apply near the ends of subduction zones, where the boundary conditions become $3 \mathrm{D}$ and may involve other forces that can influence the coupling. Examples of anomalous coupling arising from such effects, described earlier, are at the south end of the Honshu system where it approaches a triple junction with the Philippine Sea Plate and the south end of the Hikurangi trough where it impinges upon the continental Chatham Rise. Such effects may also take place within the interior of subduction zones: we gave an example of the possible effect of the collision of the Cocos Ridge on producing the anomalously low coupling in adjacent Nicaragua.

[93] It has previously been noted that decoupled subduction zones in Group A may locally become coupled at the sites of seamount subduction owing to the increase of normal stress that arises from the subduction of the extra volume of the seamount [Scholz and Small, 1997]. A more recently described example of that phenomenon is the case of the 1994 Java tsunami earthquake [Abercrombie et al., 2001].

[94] What remains to be discussed are the observations that highly coupled regions in Group $\mathrm{C}$ often contain significant areas of low coupling. Examples of this have been found in the Aleutians, Alaska, Sumatra and Peru. There has been some speculation on what geological or geophysical situations may favor the location of asperities [Song and Simons, 2003; Wells et al., 2003]. However, in the case of Group C subduction zones, high coupling is expected to be the norm, so the relevant question is what gives rise to the low coupling regions?

[95] As described in Section 2.2, neighboring stuck patches of unstable regions passively drag along conditionally stable regions. Therefore any conditionally stable region that is sufficiently distant from adjacent stuck patches will be relatively free to creep and will have low coupling. An earthquake originating at a neighboring unstable area may rupture such a region, but the coseismic slip in that region will be low because of the low accumulated seismic flux there. That description seems to fit the central low coupling zone ruptured by the 1964 Alaska earthquake [Freymueller et al., 2008]. It also fits the low coupling zone at Atka [Cross and Freymueller, 2007]. The 1957 earthquake ruptured through that sector but with very low slip [Johnson et al., 1994]. Similarly, past earthquakes have ruptured through the low coupling zones in Sumatra [Chlieh et al., 2008].

[96] At present we recognize these low coupling regions without offering any specific mechanism for their origin. The ideas of Wells et al. [2003] and Song and Simons [2003] that asperities are associated with fore-arc basins and gravity lows do not work well with the cases we study. The structure of the 1964 Alaska earthquake, with asperities at both ends and a slip minimum in between, closely matches the pattern of coupling found in the interseismic period. However, neither of those seem to correspond to any clear pattern found in the gravity field or the presence or absence of fore-arc basins [Freymueller et al., 2008; Wells et al., 2003]. In the Atka case Wells et al. predicted high coupling adjacent to the Atka basin, whereas Cross and Freymueller [2007] subsequently found low coupling. And, as we mentioned before, Song and Simons [2003] incorrectly predicted low coupling in the Kuriles seismic gap that was subsequently ruptured in the $M_{w} 8.3$ earthquake of 2006 .

[97] Based on a model in which the Andes are supported by stresses along the adjacent subduction boundary, Lamb and Davis [2003] predicted much higher shear stresses in northern Chile and southern Peru than in southern Chile. We find no differences in the seismic coupling of those regions that would lend support to this idea.

[98] A key observation by Perfettini et al. [2010] showed another way that low coupling zones can originate in highly coupled arcs. They found that the $2007 \mathrm{M}_{\mathrm{w}} 8.0$ Pisco earthquake had a large lateral lobe of afterslip that extended some $50 \mathrm{~km}$ along strike to the southeast of its rupture. The earthquake ruptured the southern end of the central coupled zone shown in Figure 4: the large afterslip lobe occurred in the low coupling zone associated with the Nazca ridge.

[99] Afterslip is a hallmark of velocity strengthening friction [Marone et al., 1991]. Therefore, as Perfettini et al. [2010] suggested, there must be a lateral change in this part of the Peru subduction zone from a velocity weakening to a velocity strengthening material, the latter associated with the Nazca ridge. Such a material would be in the stable frictional regime and hence would not only be seismically decoupled but highly resistant to any dynamic propagation within it. This would explain why the Nazca ridge acts as a profound barrier to earthquakes (Figure 4). Perfettini et al. also observed a smaller afterslip area at the other end of the Pisco rupture, so this transition between unstable and stable areas may be patchy. Another area that resembles this is the Shumagin-Sanak region, which is both decoupled and has acted as a barrier to earthquakes arriving from the east.

[100] It has been noted in several places (Sumatra, Costa Rica) that regions of high coupling correlate with offshore islands or peninsulas. One may speculate in contrary ways about this. One explanation might be that the presence of land closer to the trench simply allows measurements there that are more sensitive to detecting coupling in regions far 
offshore. The other is that the permanent uplift associated with the seismic cycles of coupled regions [Fitch and Scholz, 1971; Sieh et al., 2008] has led to the emergence of such areas.

[101] Another notable feature is that whenever tsunamigenic earthquakes have arisen in this discourse it has always been in situations of marginal seismic coupling, ie. regions which otherwise have low coupling. One wonders if they may represent some intermediate stability state that results in their anomalously slow moment release rate. Such a condition is not currently envisioned in friction stability theory.

\subsection{Properties of Asperities}

[102] It is clear from the above descriptions that there is a strong correlation of asperities with areas of high coupling. It is also clear, in regions where we have evidence of different types of earthquake re-rupturing the same areas, that this is not a case of rigorous one-to-one correspondence. In Honshu, Hokkaido, Cascadia, and south Chile, to cite the more obvious examples, there is a pattern in which large or great earthquakes rupture portions of a plate interface sector at relatively frequent intervals punctuated by much less frequent giant earthquakes with rupture zones that encompass those of several of the intervening smaller events. This behavior is in accord with the theory, which explains that the coupling coefficient, which is a permanent feature and controls the seismic flux accumulation rate, does not define the net seismic flux accumulation and hence acts only as a flexible template for the coseismic rupture zones and slip distributions of subsequent earthquakes. An interpretation of the observed pattern is that when the areas of high coupling are out of phase, local ruptures dominate, and that the giant earthquakes occur at the infrequent times when several high coupling patches are nearly in phase.

[103] To address the common identification of asperities with 'strong' areas, we point out that for frictional failure, the shear strength is $\tau=\mu_{s} \bar{\sigma}$. To the extent that asperities are associated with unstable regions, which have high values of $\bar{\sigma}$, they are indeed high strength regions. The misconception is in believing that they are also regions of high friction, $\mu_{\mathrm{s}}$. We have pointed out that unstable and conditionally stable regions do not seem to be identifiable by gross geological or geophysical signatures. This may be because this difference may actually be of second order, depending on only minor differences in normal stress, and not in any gross difference in $\mu_{\mathrm{s}}$.

[104] On the other hand, in the cases in which we think that there are anomalous velocity-strengthening materials present that are responsible for differences in behavior, like the Nazca ridge, low friction may possibly also be the case, because those two properties often go hand in hand [Ikari et al., 2011] (viz., in the case of the creeping section of the San Andreas fault, it has been shown that this is the result of the presence there of an unusual material, saponite, which has both very low friction and is velocitystrengthening [Carpenter et al., 2011; Lockner et al., 2011])

\subsection{Origin of the Complexity}

[105] Although we have described the earthquake generating properties of each subduction zones by means of a single parameter, the seismic coupling coefficient, it is clear that the seismic flux release process itself is complex. We have, in the introduction, explained that much of this complexity arises from heterogeneity in seismic coupling. We ascribed much of that heterogeneity to variations in normal stress. The success of the SC95 model in predicting the first order differences in coupling between the subduction zones validates that claim. Locally, however, there are likely to be other influences on coupling. The Nazca ridge, for example, exhibits velocity strengthening which most likely arises from a difference in material. Geometrical effects, such as bends and subducting seamounts, can also locally affect coupling.

[106] The temporal clustering of great earthquakes, that we have noted in several cases (i.e., Sumatra, Central Peru, Central Chile), results from same mechanisms that cause large earthquake triggering and the synchronization of crustal faults [Scholz, 2010; Stein, 1999]. Prime examples, from the Nankai trough, are the two great Ansei earthquakes of 1854 that ruptured adjoining areas $32 \mathrm{~h}$ apart, and the 1944 Tonankai and 1946 Nankaido earthquakes that reruptured much of the same zones with a longer time delay.

[107] If these two effects, heterogeneity of coupling and earthquake interaction were removed, would the underlying physics be simple? This does seem to be the case, as demonstrated by the example of Oaxaca. There, coupling is found to be an isolated bull's eye target that is ruptured in nearly identical earthquakes repeated with near perfect periodicity.

\section{Conclusions}

[108] We have presented, for many of the world's subduction zones, geodetic estimates of seismic coupling obtained from GPS measurements of upper plate deformation during the interseismic period. We compared those with new estimates of seismic coupling obtained from seismological data. The results show that with a few notable exceptions the results using the two methods agree to within about $10 \%$. The seismological estimates have been greatly improved over those made 20-30 years ago because of an abundance of paleoseismological data that greatly extended the temporal history of the largest earthquakes and by the occurrence, in the intervening years, of an unusual number of great and giant earthquakes that have filled in some of the most critical holes in the seismic record.

[109] The data also, again with a few notable exceptions, support the frictional instability theory of seismic coupling, and in particular, the test of that theory made by Scholz and Campos [1995]. Overall, the results support their prediction that high coupling occurs for subduction zones subjected to high normal forces with a switch to low coupling occurring fairly abruptly as the normal force decreases below a critical value.

[110] The exceptional cases are quite interesting. In a number of such cases we have been able to make plausible arguments as to why they may differ from the simple SC95 model. Other cases remain unexplained. The most puzzling are zones of low coupling that occur within otherwise highly compressional subduction zones, such as the low-coupled zone in the central region of the 1964 Alaska rupture zone and the decoupled Shumagin-Sanak sector of the Aleutians. 
[111] The seismic coupling theory provides a simple explanation of asperities. They correspond with regions of high accumulated seismic flux and hence correlate with areas of high coupling. Because regions in the unstable frictional regime, which are a permanent feature of the subduction interface, control highly coupled areas, asperities also have a semblance of permanence - they may be said to be persistent rather than permanent. However, because the phase of the seismic flux accumulation rate depends on earthquake history it varies between seismic cycles, as do the rupture zones and asperities of large earthquakes.

[112] Acknowledgments. We thank Lynn Sykes and Goran Ekstrom for helpful reviews. Jaime Campos was partially supported by Chilean Program FONDECYT 1100429. CHS thanks Y.

\section{References}

Abe, K. (1979), Size of great earthquakes of 1837-1974 inferred from Tsunami data, J. Geophys. Res., 84, 1561-1568, doi:10.1029/ JB084iB04p01561.

Abercrombie, R. E., M. Antolik, K. Felzer, and G. Ekström (2001), The 1994 Java tsunami earthquake: Slip over a subducting seamount, J. Geophys. Res., 106, 6595-6607, doi:10.1029/2000JB900403.

Abidin, H. Z., et al. (2009), Crustal deformation studies in Java (Indonesia) using GPS, J. Earthquake Tsunami, 3, 77-88, doi:10.1142/ S1793431109000445

Ammon, C. J., et al. (2005), Rupture process of the 2004 Sumatra-Andaman earthquake, Science, 308, 1133-1139, doi:10.1126/science.1112260.

Ammon, C. J., H. Kanamori, T. Lay, and A. A. Velasco (2006), The 17 July 2006 Java tsunami earthquake, Geophys. Res. Lett., 33, L24308, doi:10.1029/2006GL028005.

Ando, M. (1975), Source mechanisms and tectonic significance of historical earthquakes along the Nankai trough, Tectonophysics, 27, 119-140, doi:10.1016/0040-1951(75)90102-X.

Aoki, Y., and C. H. Scholz (2003), Interseismic deformation at the Nankai subduction zone and the Median Tectonic Line, southwest Japan, J. Geophys. Res., 108(B10), 2470, doi:10.1029/2003JB002441.

Atwater, B. F. (1987), Evidence for great Holocene earthquakes along the outer coast of Washington State, Science, 236, 942-944, doi:10.1126/ science.236.4804.942.

Atwater, B. F., and E. Hemphill-Haley (1997), Recurrence intervals for great earthquakes of the past 3500 years at the northeastern Willapa Bay, Washington, U.S. Geol. Surv. Prof. Paper, 1576, 108 pp.

Barrientos, S. E., and S. N. Ward (1990), The 1960 Chile earthquake: Inversion for slip distribution from surface deformations, Geophys. J. Int., 103 , 589-598, doi:10.1111/j.1365-246X.1990.tb05673.x.

Beavan, J., et al. (2010), Near-simultaneous great earthquakes at Tongan megathrust and outer rise in September 2009, Nature, 466, 959-963, doi:10.1038/nature09292

Bejar-Pizarro, M., et al. (2010), Asperities and barriers on the seismogenic zone in north Chile: State-of-the-art after the $2007 \mathrm{Mw} 7.7$ Tocopilla earthquake inferred by GPS and InSAR data, Geophys. J. Int., 183, 390-406, doi:10.1111/j.1365-246X.2010.04748.x.

Boyd, T. M., E. R. Engdahl, and W. Spence (1995), Seismic cycles along the Aleutian Arc: Analysis of seismicity from 1957 through 1991, J. Geophys. Res., 100, 621-644, doi:10.1029/94JB02641.

Briggs, R. W., et al. (2006), Deformation and slip along the Sunda Megathrust in the great 2005 Nias-Simeulue earthquake, Science, 311, 1897-1901, doi:10.1126/science.1122602.

Briggs, R. W., K. Sieh, W. H. Amidon, J. Galetzka, D. Prayudi, I. Suprihanto, N. Sastra, B. Suwargadi, D. Natawidjaja, and T. G. Farr (2008), Persistent elastic behavior above a megathrust rupture patch: Nias island, West Sumatra, J. Geophys. Res., 113, B12406, doi:10.1029/ 2008JB005684.

Brune, J. N., and G. R. Engen (1969), Exitation of mantle Love waves and definition of mantle wave magnitude, Bull. Seismol. Soc. Am., 59 923-933.

Brune, S., et al. (2009), Submarine landslides at the eastern Sunda margin: Observations and tsunami impact assessment, Nat. Hazards, 54, 547-562, doi:10.1007/s11069-009-9487-8.

Burgmann, R., M. G. Kogan, G. M. Steblov, G. Hilley, V. E. Levin, and E. Apel (2005), Interseismic coupling and asperity distribution along the Kamchatka subduction zone, J. Geophys. Res., 110, B07405, doi: $10.1029 / 2005 J B 003648$
Carpenter, B. M., C. Marone, and D. M. Saffer (2011), Weakness of the San Andreas fault revealed by samples from the active fault zone, Nat. Geosci., 4, 251-254, doi:10.1038/ngeo1089.

Carver, G., and G. Plafker (2008), Paleoseismicity and neotectonics of the Aleutian subduction zone: An Overview, in Active Tectonics and Seismic Potential of Alaska, Geophys. Monogr. Ser., vol. 179, edited by J. Freymueller et al., pp. 43-63, AGU, Washington, D. C., doi:10.1029/ 179GM03.

Chlieh, M., et al. (2004), Crustal deformation and fault slip during the seismic cycle in the north Chile subduction zone, from GPS and InSAR observations, Geophys. J. Int., 158, 695-711, doi:10.1111/j.1365-246X. 2004.02326.x.

Chlieh, M., J. P. Avouac, K. Sieh, D. H. Natawidjaja, and J. Galetzka (2008), Heterogeneous coupling of the Sumatran megathrust constrained by geodetic and paleogeodetic measurements, J. Geophys. Res., 113, B05305, doi:10.1029/2007JB004981.

Christensen, D. H., and S. L. Beck (1994), The rupture process and tectonic implications of the great 1964 Prince William Sound earthquake, Pure Appl. Geophys., 142, 29-53, doi:10.1007/BF00875967.

Cifuentes, I. L., and P. G. Silver (1989), Low-frequency source characteristics of the great 1960 Chilean earthquake, J. Geophys. Res., 94, 643-663, doi:10.1029/JB094iB01p00643

Cisternas, M., et al. (2005), Predecessors of the giant 1960 Chile earthquake, Nature, 437, 404-407, doi:10.1038/nature03943.

Comte, D., and M. Pardo (1991), Reappraisal of great historical earthquakes in northern Chile and southern Peru seismic gaps, Nat. Hazards, 4 , 23-44, doi:10.1007/BF00126557.

Correa-Mora, F., et al. (2008), Interplate coupling and transient slip along the subduction interface beneath Oaxaca, Mexico, Geophys. J. Int., 175, 269-290, doi:10.1111/j.1365-246X.2008.03910.x.

Correa-Mora, F., et al. (2009), GPS-derived coupling estimates fro the Central America subduction zone and volccanic arc faults: El Salvado, Honduras, and Nicaragua, Geophys. J. Int., 179, 1279-1291, doi:10.1111/ j.1365-246X.2009.04371.x.

Cross, R. S., and J. T. Freymueller (2007), Plate coupling variation and block translation in the Andreanof segment of the Aleutian arc determined by subduction zone modeling using GPS data, Geophys. Res. Lett. 34, L06304, doi:10.1029/2006GL028970.

Cross, R. S., and J. T. Freymueller (2008), Evidence for and implications of a Bering plate based on geodetic measurements from the Aleutians to western Alaska, J. Geophys. Res., 113, B07405, doi:10.1029/ 2007JB005136.

Das, S., and C. Henry (2003), Spatial relation between main earthquake slip and its aftershock distribution, Rev. Geophys., 41(3), 1013, doi:10.1029/ 2002RG000119.

Das, S., and B. V. Kostrov (1990), Inversion for seismic slip rate history and distribution with stabilizing constraints: Application to the 1986 Andreanof Islands earthquake, J. Geophys. Res., 95, 6899-6913, doi:10.1029/JB095iB05p06899.

Davies, J., et al. (1981), Shumagin seismic gap, Alaska Peninsula: History of great earthquakes, tectonic setting, and evidence for high seismic potential, J. Geophys. Res., 86, 3821-3855, doi:10.1029/JB086iB05p03821.

Dorbath, L., A. Cisternas, and C. Dorbath (1990), Assessment of the size of large and great historical earthquakes in Peru, Bull. Seismol. Soc. Am., 80 551-576.

Estabrook, C. H., and T. M. Boyd (1992), The Shumagin Islands, Alaska earthquake of 31 May 1917, Bull. Seismol. Soc. Am., 82, 755-773.

Estabrook, C. H., K. Jacob, and L. R. Sykes (1994), Body wave and surface wave analysis of large and great earthquakes along the Eastern Aleutian Arc, 1923-1993: Implications for future events, J. Geophys. Res., 99, $11,643-11,662$

Fitch, T. J., and C. H. Scholz (1971), Mechanism of underthrusting in southwest Japan: A model of convergent plate interactions, J. Geophys. Res., 76, 7260-7292, doi:10.1029/JB076i029p07260.

Fletcher, H. J., J. Beavan, J. Freymueller, and L. Gilbert (2001), High interseismic coupling of the Alaska subduction zone SW of Kodiak island inferred from GPS data, Geophys. Res. Lett., 28, 443-446, doi:10.1029/ 2000GL012258.

Fournier, T. J., and J. Freymueller (2007), Transition from locked to creeping subduction in the Shumagin region, Alaska, Geophys. Res. Lett., 34 , L06303, doi:10.1029/2006GL029073.

Franco, S. I., et al. (2005), Propagation of the 2001-2002 silent earthquake and interplate coupling in the Oaxaca subductions zone, Mexico, Earth Planets Space, 57, 973-985.

Freymueller, J. T., and J. Beavan (1999), Absence of strain accumulation in the western shumagin segment of the Alaska subduction zone, Geophys Res. Lett., 26, 3233-3236, doi:10.1029/1999GL008356.

Freymueller, J., H. Woodard, S. C. Cohen, R. Cross, J. Elliott, C. F. Larsen, S. Hreinsdóttir, and C. Zweck (2008), Active deformation in 
Alaska, based on 15 years of GPS measurements, in Active Tectonics and Seismic Potential of Alaska, Geophys. Monogr. Ser., vol. 179 edited by J. Freymueller et al., pp. 1-42, AGU, Washington, D. C., doi:10.1029/179GM02.

Goldfinger, C., C. H. Nelson, and J. E. Johnson (2003), Holocene earthquake records from the Cascadia subduction zone and northern San Andreas fault based on precise dating of offshore turbidites, Annu. Rev. Earth Planet. Sci., 31, 555-577, doi:10.1146/annurev.earth.31.100901.141246.

Goldfinger, C., et al. (2008), Late holocene ruplture of the northern San Andreas fault and possible stress linkage to the Cascadia subduction zone, Bull. Seismol. Soc. Am., 98, 861-889, doi:10.1785/0120060411.

Hanifa, N. R., F. Kimata, T. Sagiya, C. Subarya, H. Z. Abidin, and I. Meilano (2010), Interplate coupling model in West Java Trench, Indonesia, based on GPS data , AbstractG41C-03 presented at 2010 Fall Meeting, AGU, San Francisco, Calif., 1-17 Dec.

Hashimoto, C., et al. (2009), Interplate seismogenic zones along the KurilJapan trench inferred from GPS data inversion, Nat. Geosci., 2, 141-144, doi:10.1038/ngeo421.

Heki, K., and T. Kataoka (2008), On the biannually repeating slow-slip events at the Ryukyu Trench, southwestern Japan, J. Geophys. Res., 113, B11402, doi:10.1029/2008JB005739.

Hergert, T., and O. Heidback (2006), New insights into the mechanism of postseismic stress relaxation examplified bye the 23 June $2001 \mathrm{Mw}=$ 8.4 earthquake in southern Peru, Geophys. Res. Lett., 33, L02307, doi:10.1029/2005GL024858.

Hutchinson, I., and A. L. Crowell (2007), Recurrence and extent of great earthquakes in southern Alaska during the late holocene from an analysis of the radiocarbon record of land-level change and village abandonment, Radiocarbon, 49, 1323-1385.

Hyndman, R. D., and K. Wang (1995), The rupture zone of Cascadia great earthquakes from current deformation and the thermal regime, J. Geophys. Res., 100, 22,133-22,154.

Ide, S., F. Imamura, Y. Yoshida, and K. Abe (1993), Source characteristics of the Nicaraguan tsunami earthquake of September 2, 1992, Geophys. Res. Lett., 20, 863-866, doi:10.1029/93GL00683.

Ide, S., A. Baltay, and G. C. Beroza (2011), Shallow dynamic overshoo and energetic deep rupture in the $2011 \mathrm{Mw}$ Tohoku-oki earthquake, Science, 332, 1426-1429, doi:10.1126/science.1207020.

Ikari, M. J., C. Marone, and D. M. Saffer (2011), On the relation between fault strength and frictional stability, Geology, 39, 83-86.

Ito, T., S. Yoshioka, and S. Miyazaki (1999), Interplate coupling in southwest Japan deduced from inversion analysis of GPS data, Phys. Earth Planet. Inter., 115, 17-34, doi:10.1016/S0031-9201(99)00063-1.

Jankaew, K., et al. (2008), Medieval forewarning of the 2004 Indian Ocean tsunami in Thailand, Nature, 455, 1228-1231, doi:10.1038/nature 07373.

Jarrard, R. D. (1986), Relations among subduction parameters, Rev. Geophys., 24, 217-284, doi:10.1029/RG024i002p00217.

Johnson, J. M., and K. Satake (1999), Asperity distribution of the great Kamchatka earthquake and its relation to future earthquake potential in Kamchatka, Pure Appl. Geophys., 154, 541-553.

Johnson, J. M., et al. (1994), The 1957 great Aleutian earthquake, Pure Appl. Geophys., 142, 3-28, doi:10.1007/BF00875966.

Johnson, J. M., K. Satake, S. R. Holdahl, and J. Sauber (1996), The 1964 Prince William Sound earthquake: Joint inversion of tsunami and geodetic data, J. Geophys. Res., 101, 523-532, doi:10.1029/95JB02806.

Kanamori, H. (1977), The energy release in great earthquakes, J. Geophys. Res., 82, 2981-2987, doi:10.1029/JB082i020p02981.

Kanamori, H., and J. J. Cipar (1974), Focal process of the great Chilean earthquake, May 22, 1960, Phys. Earth Planet. Inter., 9, 128-136, doi:10.1016/0031-9201(74)90029-6.

Kanamori, H., and K. C. McNally (1982), Variable rupture mode of the subduction zone along the Equador-Colombia coast, Bull. Seismol. Soc. Am., 72, 1241-1253.

Kao, H. (1998), Can great earthquakes occur in the southernmost Ryukyu Arc-Taiwan region?, Terr. Atmos. Oceanic Sci., 9, 487-508.

Karig, D. E. (1970), Kermadec Arc-New Zealand tectonic confluence, N. Z. J. Geol. Geophys., 13, 21-29, doi:10.1080/00288306.1970.10428203.

Kausel, E., and J. Campos (1992), Of northern Chile and its relation to the seismic potential of the region, Phys. Earth Planet. Inter., 72, 220-235, doi:10.1016/0031-9201(92)90203-8.

Kelleher, J., and W. McCann (1976), Bouyant zones, great earthquakes, and unstable boundaries of subduction, J. Geophys. Res., 81, 4885-4896, doi:10.1029/JB081i026p04885.

Kelsey, H. M., et al. (2005), Tsunami history of an Oregon coastal lake reveals a $4600 \mathrm{yr}$ record of great earthquakes on the Cascadia subduction zone, Geol. Soc. Am. Bull., 117, 1009-1032, doi:10.1130/B25452.1.

Konca, A. O., et al. (2008), Partial rupture of a locked patch of the Sumatra megathrust during the 2007 earthquake sequence, Nature, 456, 631-635, doi: 10.1038 /nature 07572 .
Kostoglodov, V., S. K. Singh, J. A. Santiago, S. I. Franco, K. M. Larson, A. R. Lowry, and R. Bilham (2003), A large silent earthquake in the Guerrero seismic gap, Mexico, Geophys. Res. Lett., 30(15), 1807, doi:10.1029/2003GL017219.

LaFemina, P., T. H. Dixon, R. Govers, E. Norabuena, H. Turner, A. Saballos, G. Mattioli, M. Protti, and W. Strauch (2009), Fore-arc motion and Cocos Ridge collision in Central America, Geochem. Geophys. Geosyst., 10, Q05S14, doi:10.1029/2008GC002181.

Lamb, S., and P. Davis (2003), Cenozoic climate change as a possible cause for the rise of the Andes, Nature, 425, 792-797, doi:10.1038/ nature02049.

Lay, T., H. Kanamori, and L. J. Ruff (1982), The asperity model and the nature of large subduction zone earthquakes, Earthquake Predict. Res. $1,3-71$.

Lay, T., et al. (2005), The great Sumatra-Andaman earthquake of 26 December 2004, Science, 308, 1127-1133, doi:10.1126/science. 1112250 .

Lay, T., H. Kanamori, C. J. Ammon, A. R. Hutko, K. Furlong, and L. Rivera (2009), The 2006-2007 Kurile Islands great earthquake sequence, J. Geophys. Res., 114, B11308, doi:10.1029/2008JB006280.

Lay, T., et al. (2010), The 2009 Samoa-Tonga great earthquake triggered doublet, Nature, 466, 964-968, doi:10.1038/nature09214.

Lockner, D. A., et al. (2011), Low strength of deep San Andreas fault gouge from SAFOD core, Nature, 472, 82-85, doi:10.1038/nature09927.

Lorenzo-Martin, F., F. Roth, and R. J. Wang (2006), Inversion for rheological parameters from post-seismic surface deformation associated with the 1960 Valdivia earthquake, Chile, Geophys. J. Int., 164, 75-87, doi:10.1111/j.1365-246X.2005.02803.x.

Loveless, J. P., and B. J. Meade (2010), Geodetic imaging of plate motions, slip rates, and partitioning of deformation in Japan, J. Geophys. Res., 115, B02410, doi:10.1029/2008JB006248.

Loveless, J. P., and B. J. Meade (2011), Spatial correlation of interseismic coupling and coseismic rupture extent of the $2011 \mathrm{Mw}=9.0$ Tohoku-oki earthquake, Geophys. Res. Lett., 38, L17306, doi:10.1029/2011GL048561.

Marone, C. J., C. H. Scholz, and R. Bilham (1991), On the mechanics of earthquake afterslip, J. Geophys. Res., 96, 8441-8452, doi:10.1029/ 91JB00275.

Mazzotti, S., et al. (2000), Full interseismic locking of the Nankai and Japan-west Kurile subduction zones: An analysis of uniform elastic strain accumulation in Japan constrained by permanent GPS, J. Geophys. Res., 105, 13,159-13,177, doi:10.1029/2000JB900060.

McCaffrey, R. (1992), Oblique plate convergence, slip vectors, and fore-arc deformation, J. Geophys. Res., 97, 8905-8915, doi:10.1029/92JB00483.

McCaffrey, R. (1997), Statistical significance of the seismic coupling coefficient, Bull. Seismol. Soc. Am., 87, 1069-1073.

McCaffrey, R. (2008), Global frequency of magnitude 9 earthquakes, Geology, 36, 263-266, doi:10.1130/G24402A.1

McCaffrey, R., M. D. Long, C. Goldfinger, P. C. Zwick, J. L. Nabelek, C. K. Johnson, and C. Smith (2000), Rotation and plate locking at the southern Cascadia subduction zone, Geophys. Res. Lett., 27, 3117-3120, doi:10.1029/2000GL011768.

McCann, W. R., et al. (1979), Seismic gaps and plate tectonics: Seismic potential for major boundaries, Pure Appl. Geophys., 117, 1082-1147, doi:10.1007/BF00876211.

Meltzner, A. J., K. Sieh, H.-W. Chiang, C.-C. Shen, B. W. Suwargadi, D. H. Natawidjaja, B. E. Philibosian, R. W. Briggs, and J. Galetzka (2010), Coral evidence for earthquake recurrence and an A.D. 13901455 cluster at the south end of the 2004 Aceh-Andaman rupture, J. Geophys. Res., 115, B10402, doi:10.1029/2010JB007499.

Minoura, K., et al. (2001), The 869 Jogan Tsunami deposit and recurrence interval of large-scale tsunami on the Pacific coast of Japan, J. Nat. Disaster Sci., 23, 83-88.

Monecke, K., et al. (2008), A 1,000 year sediment record of tsunami recurrence in northern Sumatra, Nature, 455, 1232-1234, doi:10.1038/ nature 07374 .

Nakamura, M. (2009), Fault model of the 1771 Yaeyama earthquake along the Ryukyu trench estimated from the devastating tsunami, Geophys. Res. Lett., 36, L19307, doi:10.1029/2009GL039730.

Nanayama, F., et al. (2003), Unusually large earthquakes inferred from tsunami deposits along Kurile trench, Nature, 424, 660-663, doi:10.1038/ nature01864.

Nanayama, F., et al. (2007), Nine unusually large tsunami deposits from the past 4000 years at Kiritappu marsh along the southern Kuril trench, Sediment. Geol., 200, 275-294, doi:10.1016/j.sedgeo.2007.01.008.

Natawidjaja, D. H., K. Sieh, M. Chlieh, J. Galetzka, B. W. Suwargadi, H. Cheng, R. L. Edwards, J.-P. Avouac, and S. N. Ward (2006), Source parameters of the great Sumatran megathrust earthquakes of 1797 and 1833 inferred from coral microatolls, J. Geophys. Res., 111, B06403, doi:10.1029/2005JB004025. 
Natawidjaja, D. H., K. Sieh, J. Galetzka, B. W. Suwargadi, H. Cheng, R. L. Edwards, and M. Chlieh (2007), Interseismic deformation above the Sunda Megathrust recorded in coral microatolls of the Mentawai islands, West Sumatra, J. Geophys. Res., 112, B02404, doi:10.1029/ 2006JB004450

Nettles, M., G. Ekstrom, and H. C. Koss (2011), Centroid-moment-tensor analysis of the 2010 Tohoku earthquake and its larger foreshocks and aftershocks, Earth Planets Space, 99, 1-9.

Newcomb, K. R., and W. R. McCann (1987), Seismic history and seismotectonics of the Sunda Arc, J. Geophys. Res., 92, 421-439, doi:10.1029 JB092iB01p00421.

Nishenko, S. P. (1985), Seismic potential for large and great interplate earthquakes along the Chilean and southern Peruvian margins of South America: A quantitative reappraisal, J. Geophys. Res., 90, 3589-3615, doi:10.1029/JB090iB05p03589.

Nishenko, S. P. (1991), Circum-Pacific seismic potential: 1989-1999, Pure Appl. Geophys., 135, 169-259, doi:10.1007/BF00880240.

Norabena, E., et al. (2004), Geodetic and seismic constraints on some seismogenic processes in Costa Rica, J. Geophys. Res., 109, B11403, doi:10.1029/2003JB002931

Obara, K. (2010), Phenomenology of deep slow earthquake family in southwest Japan: Spatiotemporal characteristics and segmentation, J. Geophys Res., 115, B00A25, doi:10.1029/2008JB006048.

Ohta, Y., et al. (2006), A large slip event and the depth of the seismogenic zone in the south central Alaska subduction zone, Earth Planet. Sci. Lett. 247, 108-116, doi:10.1016/j.eps1.2006.05.013.

Pacheco, J. F., L. R. Sykes, and C. H. Scholz (1993), Nature of seismic coupling along simple plate boundaries of the subduction type, J. Geophys Res., 98, 14,133-14,159.

Perfettini, H., et al. (2010), Seismic and aseismic slip on the central Peru megathrust, Nature, 465, 78-81, doi:10.1038/nature09062.

Peterson, E. T., and T. Seno (1984), Factors aflecting seismic moment release rates in subduction zones, J. Geophys. Res., 89, 10,233-10,248, doi:10.1029/JB089iB12p10233.

Plafker, G., and J. C. Savage (1970), Mechanism of the Chilean earthquake of May 21 and 22, 1960, Geol. Soc. Am. Bull., 81, 1001-1030, doi:10.1130/0016-7606(1970)81[1001:MOTCEO]2.0.CO;2.

Rajendran, K., et al. (2008), Age estimates of coastal terraces in the Andaman and Nicobar Islands and their tectonic implications, Tectonophysics, 455, 53-60, doi:10.1016/j.tecto.2008.05.004

Rastogi, B. K. (2006), A historical account of the earthquakes and tsunamis in the Indian Ocean, in The Indian Ocean Tsunami, edited by T. S. Murty et al., pp. 3-18, Taylor and Francis, London, doi:10.1201/9780203964439.pt1.

Rogers, G., and H. Dragert (2003), Episodic tremor and slip on the Cascadia subduction zone: The chatter of silent slip, Science, 300, 1942-1943, doi:10.1126/science.1084783.

Ruegg, J. C., et al. (2009), Interseismic strain accumulation measured by GPS in the seismic gap between Constitucion and Concepcion in Chile, Phys. Earth Planet. Inter., 175, 78-85, doi:10.1016/j.pepi.2008.02.015.

Ruff, L., and H. Kanamori (1980), Seismicity and the subduction process, Phys. Earth Planet. Inter., 23, 240-252, doi:10.1016/0031-9201(80) 90117-X.

Ruff, L., and H. Kanamori (1983), Seismic coupling and uncoupling at subduction zones, Tectonophysics, 99, 99-117, doi:10.1016/0040-1951(83) 90097-5

Sagiya, T. (1999), Interplate coupling in the Tokai District, central Japan, deduced from continuous GPS measurements, Geophys. Res. Lett., 26 , 2315-2318, doi:10.1029/1999GL900511.

Sagiya, T., and W. Thatcher (1999), Coseismic slip resolution along a plate boundary megathrust: The Nankai Trough, southwest Japan, J. Geophys. Res., 104, 1111-1129, doi:10.1029/98JB02644.

Satake, K. (1994), Mechanism of the 1992 Nicaragua tsunami earthquake, Geophys. Res. Lett., 21, 2519-2522, doi:10.1029/94GL02338.

Satake, K., K. Wang, and B. F. Atwater (2003), Fault slip and seismic moment of the 1700 Cascadia earthquake inferred from the Japanese tsunami descriptions, J. Geophys. Res., 108(B11), 2535, doi:10.1029 2003JB002521.

Savage, J. C., J. L. Svarc, W. H. Prescott, and W. K. Gross (1998), Deformation across the rupture zone of the 1964 Alaska earthquake, 19931997, J. Geophys. Res., 103, 21,275-21,283.

Savage, J. C., J. L. Svarc, and W. H. Prescott (1999), Deformation across the Alaska-Aleutian subduction zone near Kodiak, Geophys. Res. Lett. 26, 2117-2120, doi:10.1029/1999GL900471.

Sawai, Y., et al. (2009), Aperiodoic recurrence of geologically recorded tsunamis during the past 5500 years in eastern Hokkaido Japan, J. Geophys. Res., 114, B01319, doi:10.1029/2007JB005503.

Scholz, C. H. (1998), Earthquakes and friction laws, Nature, 391, 37-42, doi:10.1038/34097.
Scholz, C. H. (2002), The Mechanics of Earthquakes and Faulting, 2nd ed., 471 pp., Cambridge Univ. Press, Cambridge, U. K.

Scholz, C. H. (2010), Large earthquake triggering, clustering, and the synchronization of faults, Bull. Seismol. Soc. Am., 100, 901-909, doi: $10.1785 / 0120090309$

Scholz, C. H., and J. Campos (1995), On the mechanism of seismic decoupling and back-arc spreading in subduction zones, J. Geophys. Res., 100, $22,103-22,115$.

Scholz, C. H., and C. Small (1997), The effect of seamount subduction on seismic coupling, Geology, 25, 487-490, doi:10.1130/0091-7613(1997) $025<0487$ :TEOSSO $>2.3 . \mathrm{CO} ; 2$.

Seno, T., and T. Takano (1989), Seismotectonics at the trench-trench-trench triple junction off central Honshu, Pure Appl. Geophys., 129, 27-40, doi:10.1007/BF00874623.

Shennan, I., N. Barlow, and R. Combellick (2008), Paleoseismological records of multiple great earthquakes in southcentral Alaska: A 4000 year record at Girdwood, in Active Tectonics and Seismic Potential of Alaska, Geophys. Monogr. Ser., vol. 179, edited by J. Freymueller et al., pp. 185-200, AGU, Washington, D. C., doi:10.1029/179GM10.

Shennan, I., R. Bruhn, and G. Plafker (2009), Multi-segment earthquakes and tsunami potential of the Aleutian megathrust, Quat. Sci. Rev., 28 , 7-13, doi:10.1016/j.quascirev.2008.09.016.

Shimazaki, K., and T. Nagata (1980), Time-predictable recurrence model for large earthquakes, Geophys. Res. Lett., 7, 279-282, doi:10.1029/ GL007i004p00279.

Sieh, K., et al. (2008), Earthquake supercycles inferred from sea-level changes recorded in the corals of west Sumatra, Science, 322 , 1674-1678, doi:10.1126/science. 1163589 .

Simons, M., et al. (2011), The 2011 magnitude 9.0 Tohoku-Oki earthquake: Mosaicking the megathrust from seconds to centuries, Science, 332 1421-1425, doi:10.1126/science. 1206731 .

Song, T. A., and M. Simons (2003), Large trench-parallel gravity variations predict seismogenic behavior in subduction zones, Science, 301, 630-633, doi:10.1126/science. 1085557.

Stein, R. S. (1999), The role of stress transfer in earthquake occurrence, Nature, 402, 605-609, doi:10.1038/45144.

Stein, S., and E. A. Okal (2007), Ultralong period study of the December 2004 Indian Ocean earthquake and implications for regional tectonics and the subduction process, Bull. Seismol. Soc. Am., 97, S279-S295, doi:10.1785/0120050617.

Subarya, C., et al. (2006), Plate-boundary deformation associated with the great Sumatra-Andaman earthquake, Nature, 440, 46-51, doi:10.1038/ nature 04522.

Suwa, Y., S. Miura, A. Hasegawa, T. Sato, and K. Tachibana (2006), Interplate coupling beneath NE Japan inferred from three-dimensional displacement field, J. Geophys. Res., 111, B04402, doi:10.1029/ 2004JB003203.

Sykes, L. R. (1971), Aftershock zones of great earthquakes, seismicity gaps, and earthquake prediction for Alaska and the Aleutians, J. Geophys. Res. 76, 8021-8041, doi:10.1029/JB076i032p08021.

Sykes, L. R., and W. Menke (2006), Repeat times of large earthquakes: Implications for earthquake mechanics and long-term prediction, Bull. Seismol. Soc. Am., 96, 1569-1596, doi:10.1785/0120050083.

Sykes, L. R., J. B. Kisslinger, L. House, J. N. Davies, and K. H. Jacob (1981), Rupture zones and repeat times of great earthquakes along the Alaska-Aleutian arc, in Earthquake Prediction: An International Review, M. Ewing Ser., vol. 4, edited by D. Simpson and P. G. Richards, pp. 73-80, AGU, Washington, D.C., doi:10.1029/ME004p0073.

Thatcher, W. (1990), Order and diversity in the modes of circum-Pacific earthquake recurrence, J. Geophys. Res., 95, 2609-2623, doi:10.1029/ JB095iB03p02609.

Tichelaar, B. W., and L. J. Ruff (1993), Depth of seismic coupling along subduction zones, J. Geophys. Res., 98, 2017-2037, doi:10.1029/ 92JB02045.

Uchida, N., et al. (2009), What controls interplate coupling?: Evidence for abrupt change in the coupling across a border between two overlaying plates in the NE Japan subduction zone, Earth Planet. Sci. Lett., 283, 111-121, doi:10.1016/j.eps1.2009.04.003

Uyeda, S. (1982), Subduction zones: An introduction to comparative subductology, Tectonophysics, 81, 133-159, doi:10.1016/0040-1951(82) 90126-3.

Vargas, G., et al. (2005), Paleoseismic inferences from a hig-resolution marine sedimentary record in northern Chile $\left(23^{\circ} \mathrm{S}\right)$, Tectonophysics, 399, 381-398, doi:10.1016/j.tecto.2004.12.031

Vigny, C., et al. (2011), The 2010 M8.8 Maule megathrust earthquake of central Chile, monitored by GPS, Science, 332, 1417-1421, doi:10.1126/science.1204132. 
Wallace, L. M., and J. Beavan (2010), Diverse slow slip behavior at the Hikurangi subduction margin, New Zealand, J. Geophys. Res., 115, B12402, doi:10.1029/2010JB007717.

Wallace, L. M., J. Beavan, and D. Darby (2004), Subduction zone coupling and tectonic block rotations in the North Island, New Zealand, J. Geophys. Res., 109, B12406, doi:10.1029/2004JB003241.

Wallace, L. M., et al. (2005), Rapid microplate rotations and backarc rifting at the transition between collision and subduction, Geology, 33, 857-860, doi:10.1130/G21834.1.

Walpersdorf, A., N. Cotte, V. Kostoglodov, M. Vergnolle, M. Radiguet, J. A. Santiago, and M. Campillo (2011), Two successive slow slip events evidenced in 2009-2010 by a dense GPS network in Guerrero, Mexico, Geophys. Res. Lett., 38, L15307, doi:10.1029/2011GL048124.

Wang, K., R. Wells, S. Mazzotti, R. D. Hyndman, and T. Sagiya (2003), A revised dislocation model of interseismic deformation of the Cascadia subduction zone, J. Geophys. Res., 108(B1), 2026, doi:10.1029/ 2001JB001227
Wells, R. E., R. J. Blakely, Y. Sugiyama, D. W. Scholl, and P. A. Dinterman (2003), Basin-centered asperities in great subduction zone earthquakes: A link between slip, subsidence, and subduction erosion?, J. Geophys. Res., 108(B10), 2507, doi:10.1029/2002JB002072.

White, S. M., R. Trenkamp, and J. N. Kellogg (2003), Recent crustal deformation and the earthquake cycle along the Ecuador-Columbia subduction zone, Earth Planet. Sci. Lett., 216, 231-242, doi:10.1016/ S0012-821X(03)00535-1.

Zheng, G., R. Dmowska, and J. R. Rice (1996), Modeling earthquake cycles in the Shumagin subduction segment, Alaska, with seismic and geodetic constraints, J. Geophys. Res., 101, 8383-8392, doi:10.1029/ 95JB03461.

Zweck, C., J. T. Freymueller, and S. C. Cohen (2002), Three-dimensional elastic dislocation modeling of the postseismic response to the 1964 Alaska earthquake, J. Geophys. Res., 107(B4), 2064, doi:10.1029/ 2001JB000409. 